\title{
الغرابة في شخصيات رواية عرس الزين للكاتب الطيب الصالح
}

\author{
الاكتور فتح الرحمن محمد أحمد الجعلي

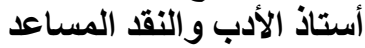 \\ كلية اللغة العربية والدراسات الاجتماعية الإداعية ـ جامعة القصيم ـ المملكة العربية السعودية \\ الايميل:yahoo.com
}

دار البحث حول الغرابة في شخصيات رواية (عرس الزين) ـأولى روايات الكاتب السوداني الطيب صالحمنطلقاً من كون الغرابة تعني : غير المألوف، وقد هدف البحث لمعرفة كيفية معالجة المؤلف لشخصيات

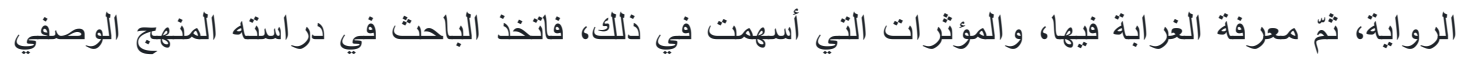
التحليلي منهجا رئيساً ، ثم استعان بالمنهج الاجتماعي لارتباط الموضوع بموضو عابهو عات اجتماعية، فدرس الظاهرة من خلال المجتمع الروائي في قرية الزين، ومجتمع المؤلف الواقعي الذي أخذ منه ثقافته؛ لما له من أثر في تصور المؤلف لثخصيات الرواية، فوجد الغرابة في شخصية الزين الذي يمثل بطل الرواية، فقد كان غريباً منذ مولده، ولازمه تكوينٌ جسديّ غريب ، و وتصرفات غريبة، الأمر الذي جعله أغرب الثخصيّات، ثمّ الثيخ

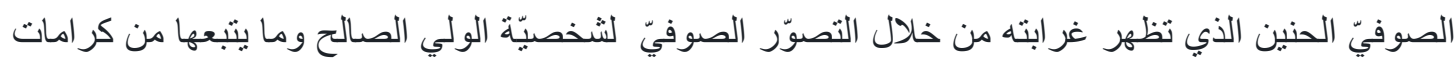

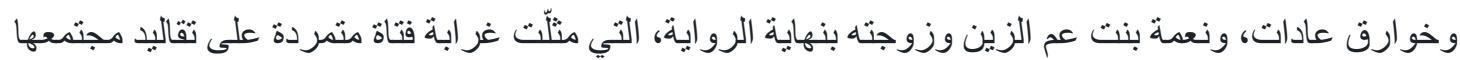

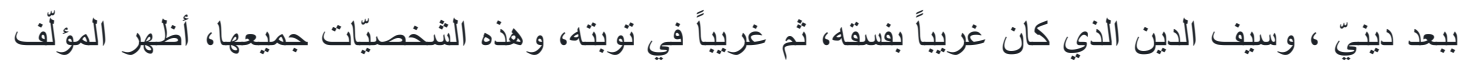
غر ابتها من خلال الأحداث، أو من خلال الوصف المباثر، وقد كانت للعوامل البيئيّة المنمثلة في المعتقدات الدينية، والتصورات الصوفية ،و القيم الاجتماعية ،والأساطير الثعبية، أثر في ذلك. وقد أوصى الباحث بمزيد من الدراسات عن الغر ابة في شخصيات و أحداث رو ايات الطبب صالح. الكلمات المفتاحية: الطيب الصالح، عرس الزين، الرواية السودانية. 


\title{
Strangeness in the Characters of the novel of Al-Taib Al-Salih "Al-Zain Wedding"
}

\author{
Dr. Fath Al-Rahman Muhammad Ahmad Al-Jali \\ Professor of literature and associate criticism \\ College of Arabic Language and Social Studies - Qassim University - KSA \\ Email: ahedfath50@yahoo.com
}

\begin{abstract}
This study revolves around the concept of strangeness in the Zain's wedding novel (Zain is the protagonist, and Zain wedding is the first novel for the Sudanese writer Tayeb Saleh). It deals with the strangeness with the sense of uncommon. It aims at explaining the strange characters in the novel; showing how the author deals with the novel characters with understanding to sense of strangeness among them; and explaining the influences contributed to this dealing. Due the association of this study with the novel author society, so, it uses the descriptive and social analysis approaches. Hence, it analyses the novelist society and the author's original community or real life society.

It finds that Zain was born with these strange characters i.e. physically; he grows with this strange body with strange attitudes that makes him the strangest personality of the Novel.

Alhaneen is a Sufi Sheikh who appears with strange character, his strangeness appears through the mystical conception of dignity. Nima is Zain's cousin and his wife, who represents the strangeness of a rebellious girl against her community traditions or its religious dimensions at the end of the novel. Seifuddin was strange in his debauchery and his repentance. The author shows the strangeness on all of these characters through events or through direct descriptions.

It is obviously that the author has influenced by the environmental factors such as religious beliefs, Sufi perceptions, social values, and popular myths. Finally, for further studies the researcher recommends conducting some studies on the strangeness in the characters and events of Tayeb Saleh novels.
\end{abstract}

Keywords: Sudanese novel, Al-Taib Al-Salih, Al-Zain Wedding. 


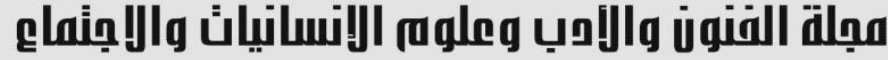

www.jalhss.com

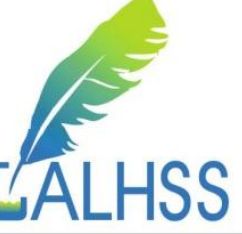

عرّف الدكتور عبد الحميد شاكر (الغرابة)، فقال: "الغرابة ضد الألفة، نوع من القلق المقيم، حالة بين الحياة

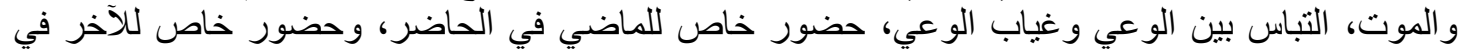

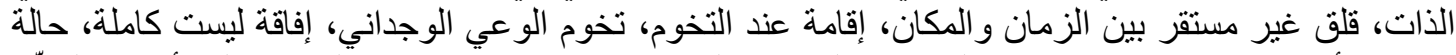

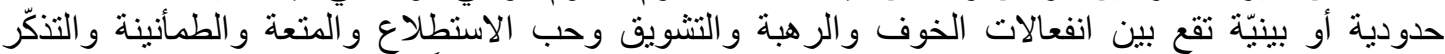

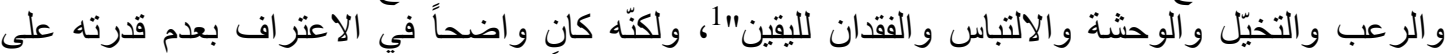

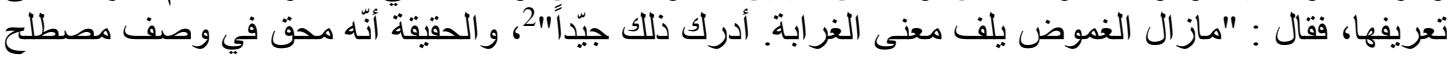

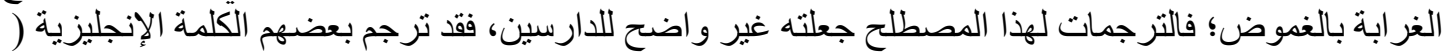

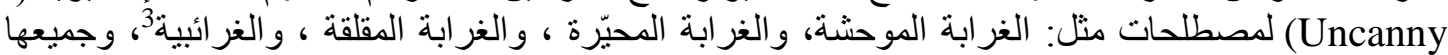

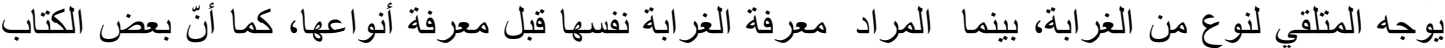

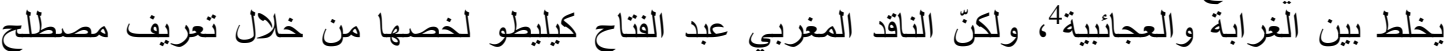

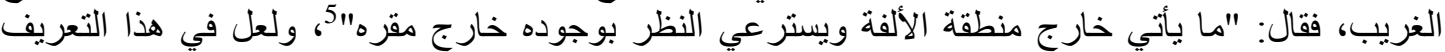

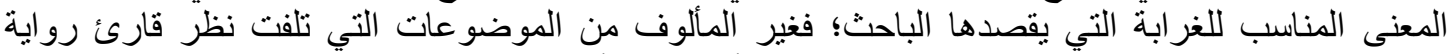

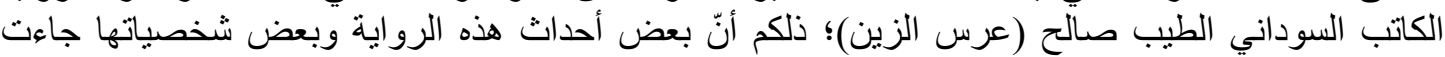

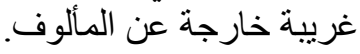

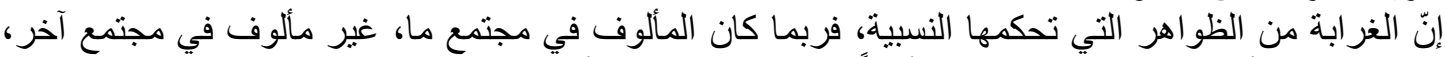

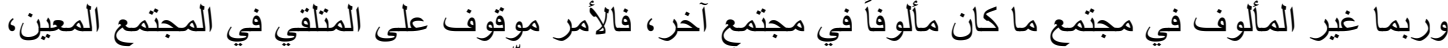

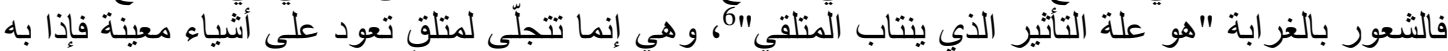

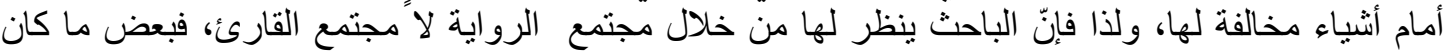

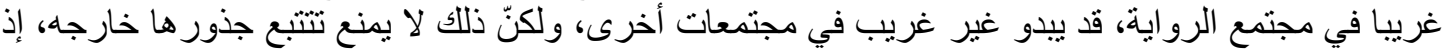

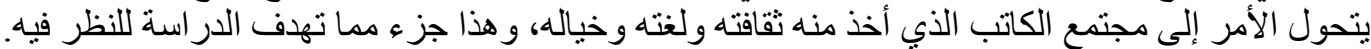

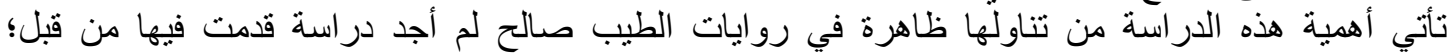

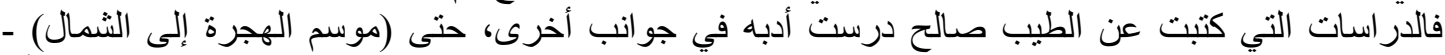

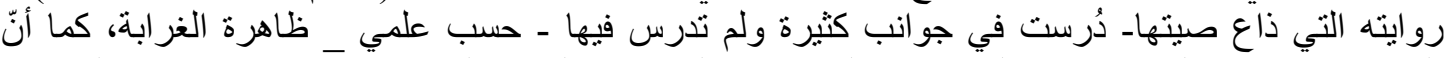

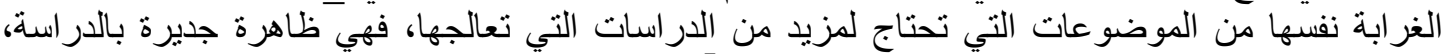

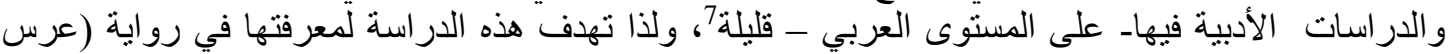

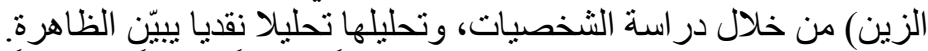

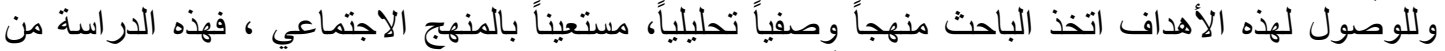

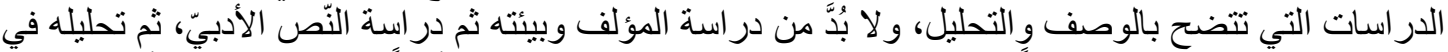

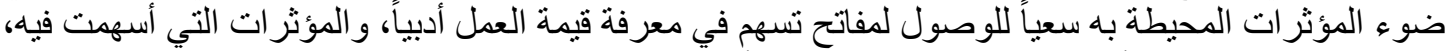

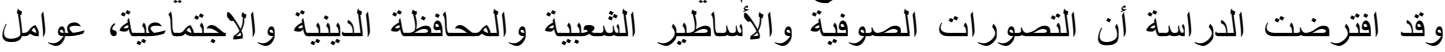

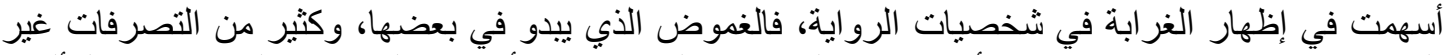

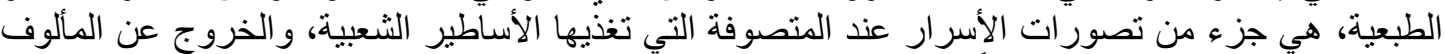

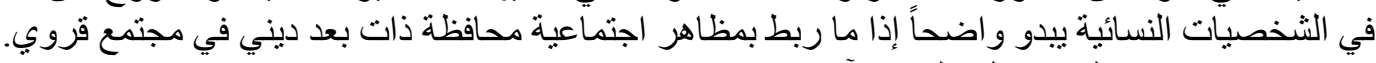
وقد جاءت تساؤلات البحث على النحو الآتي: -

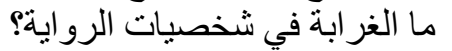

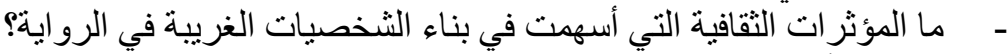

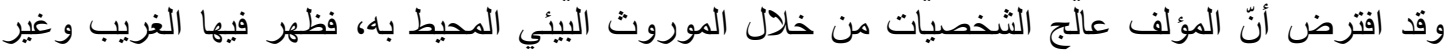

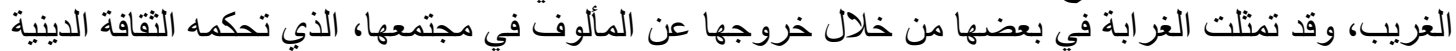

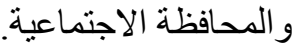
وللوصول لكل ذللك رأى الباحث إبراز ملامح من حياة المؤلف، وإلقاء الضوء على رواية عرس الزين، ثم در اسة الغر ابة في شخصياتها. 


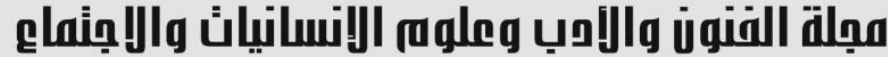

Journal of Arts, Literature, Humanities and Social Sciences
www.jalhss.com

\section{المبحث الأول \\ لمحات من حياة الطيب صالح وأدبه}

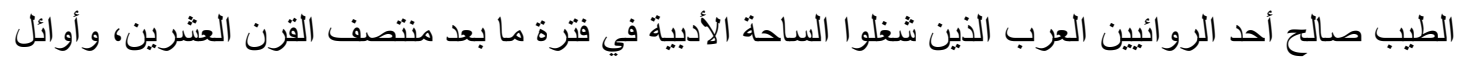

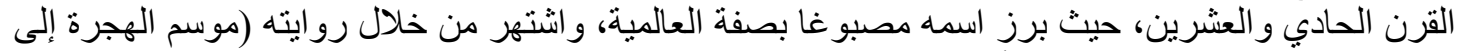

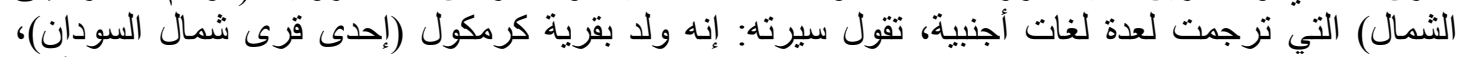

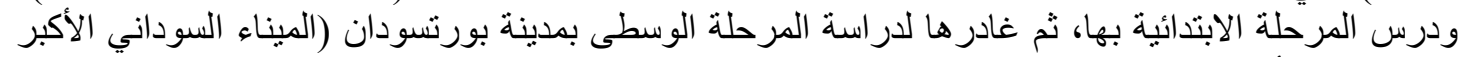

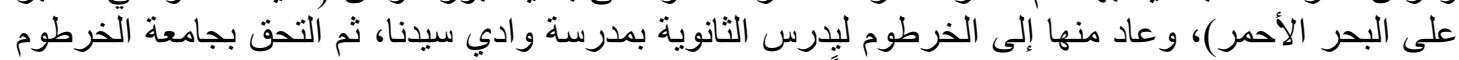

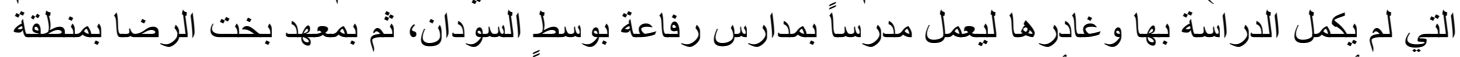

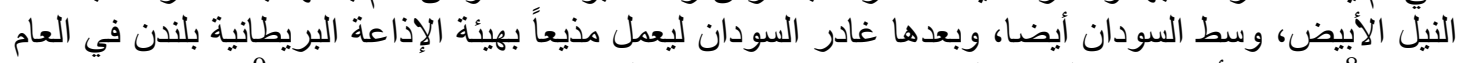

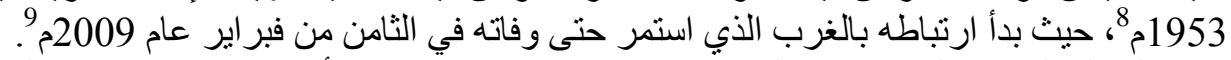

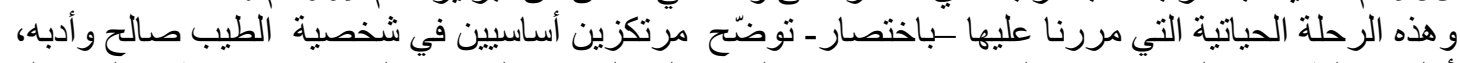

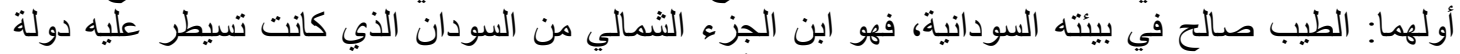

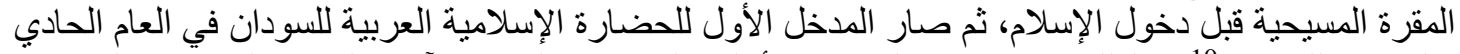

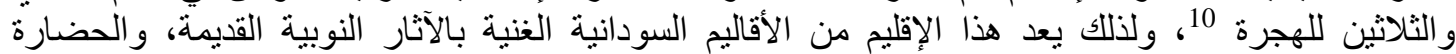

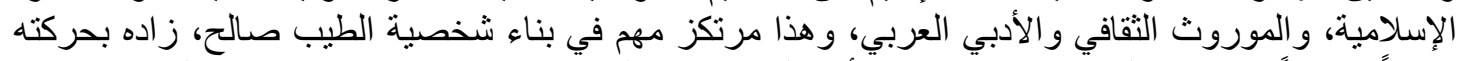

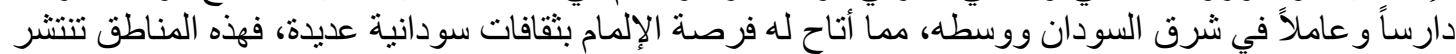

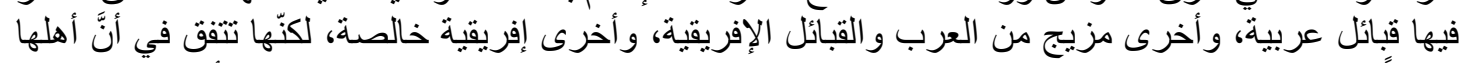

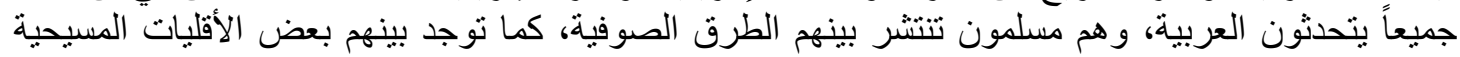

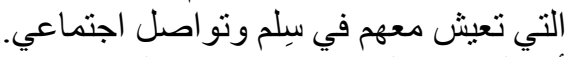

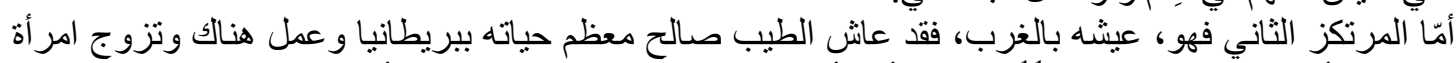

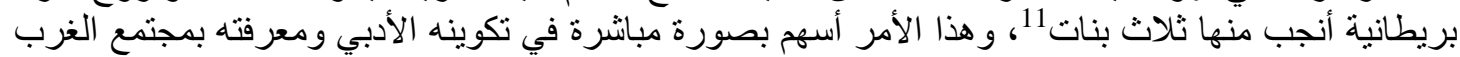

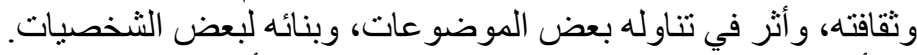

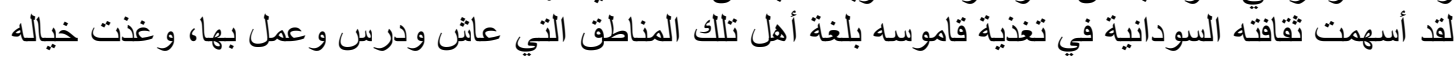

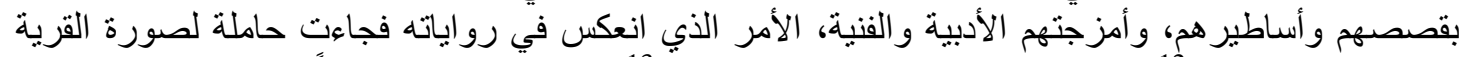

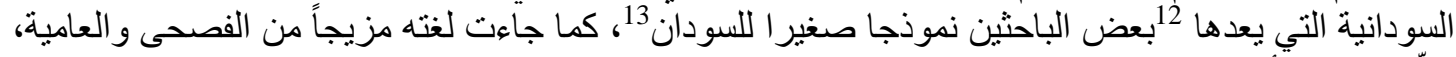

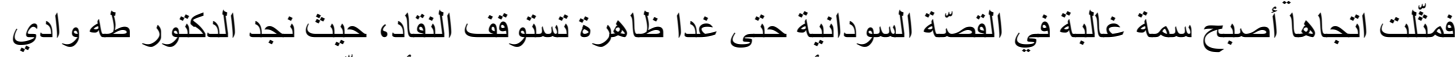

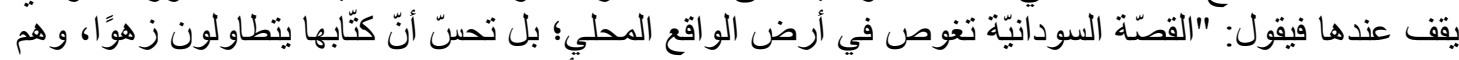

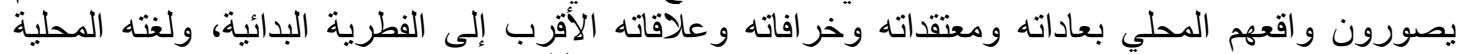

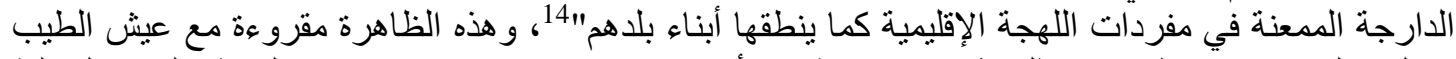

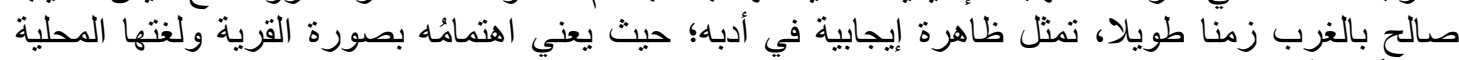

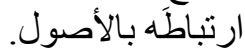

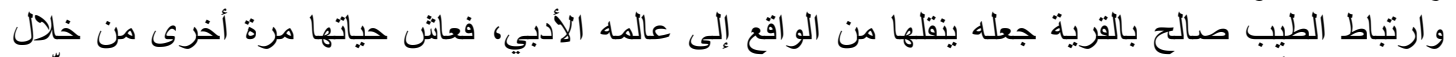

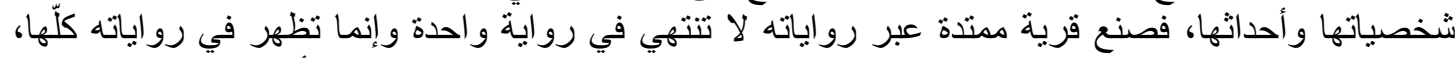

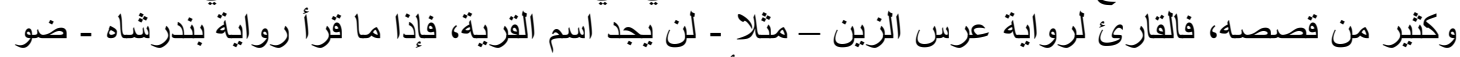

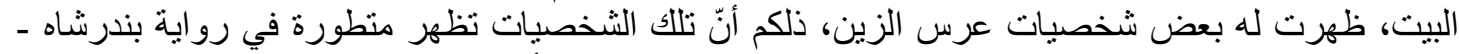

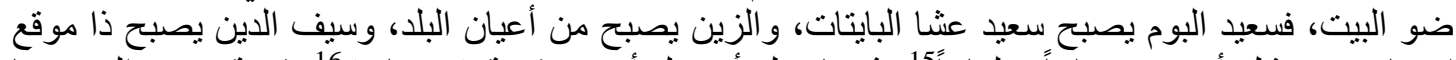

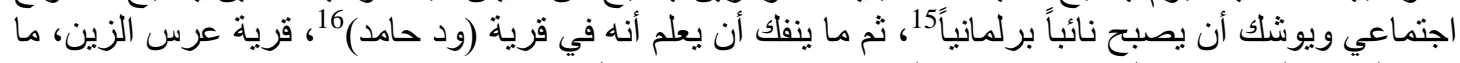

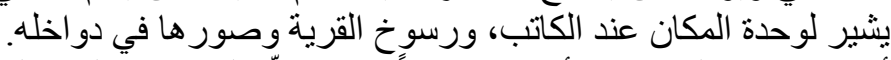

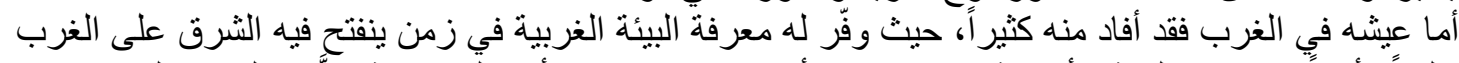

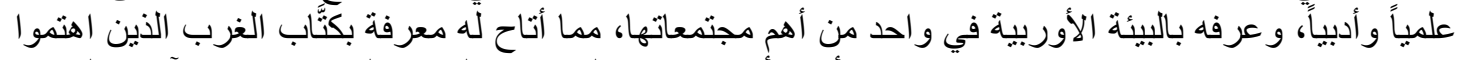

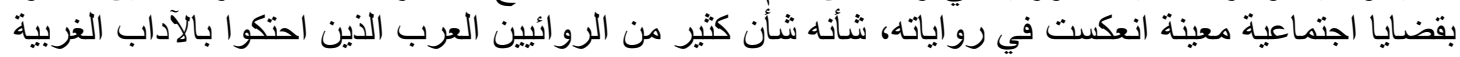




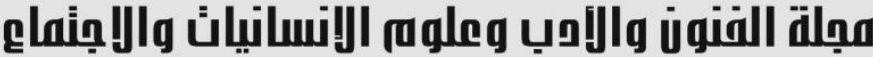

\begin{tabular}{|c|c|c|c|}
\hline 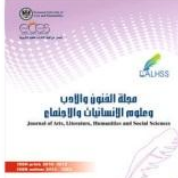 & 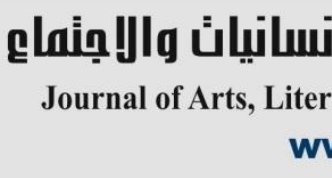 & $\begin{array}{l}\text { Jlq ügīll ïlñ } \\
\text { and Social Sciences }\end{array}$ & \\
\hline$=$ & Volume (51) Abril 2020 & العدد (51) ابريل 2020 & \\
\hline
\end{tabular}

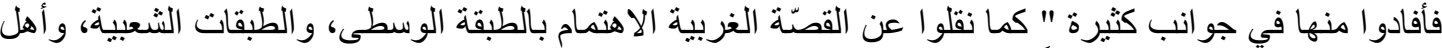

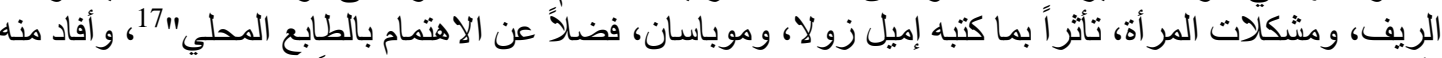

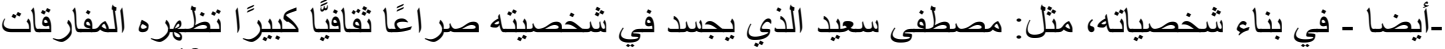

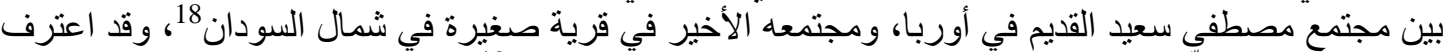

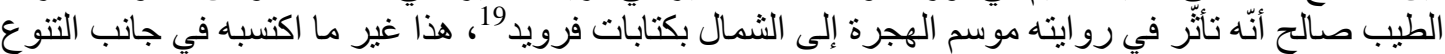

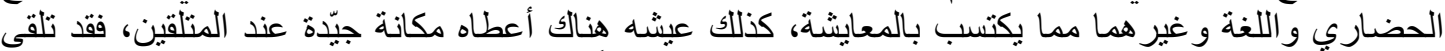

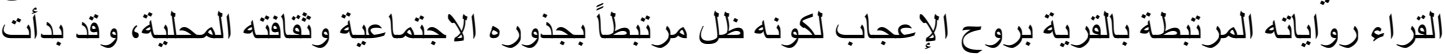

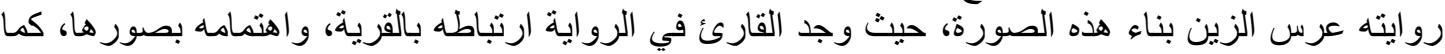

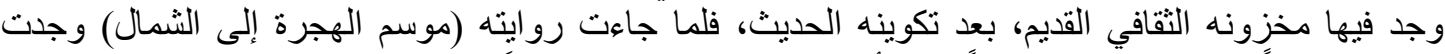

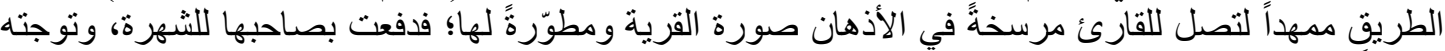

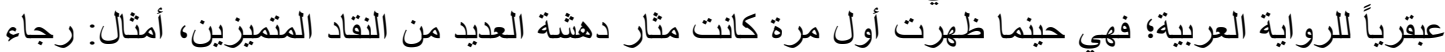

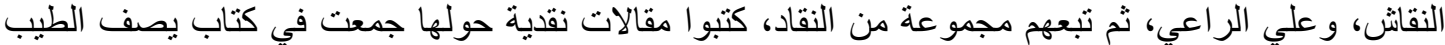

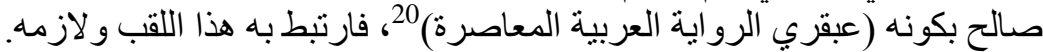

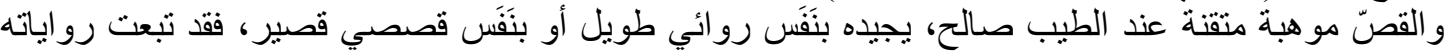

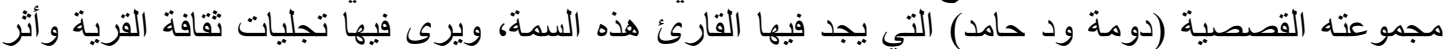

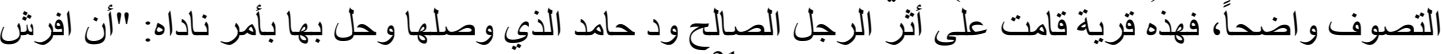

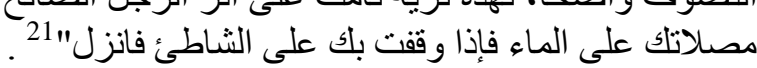

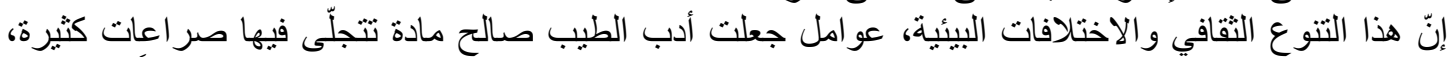

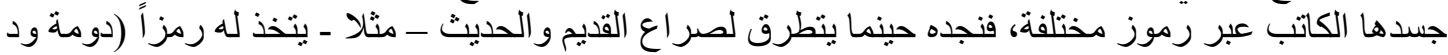

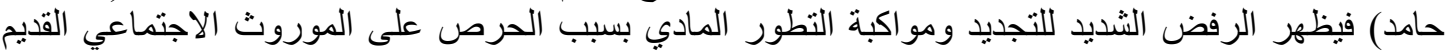

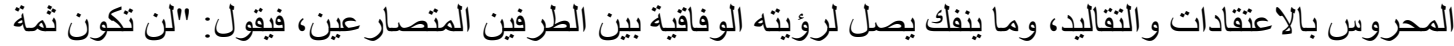

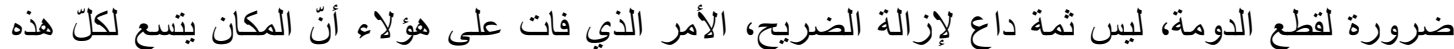

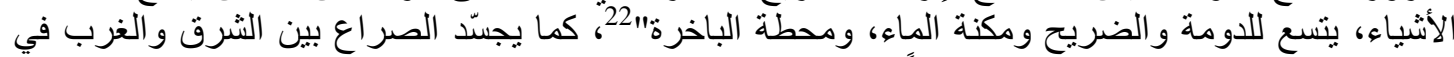

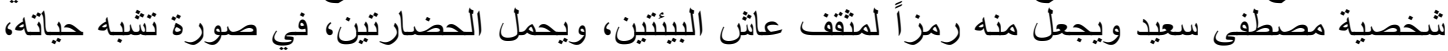

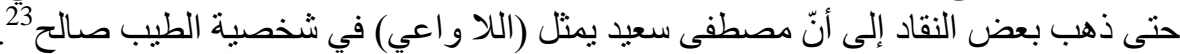

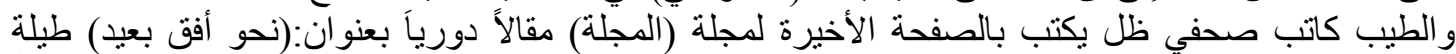
تسعينات القرن الماضي، وقد جمع تللك المقالات في عدد من الكتب تحمل اسم (مختارات)، كان أولهان بلها صدوراً

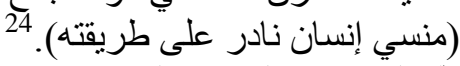

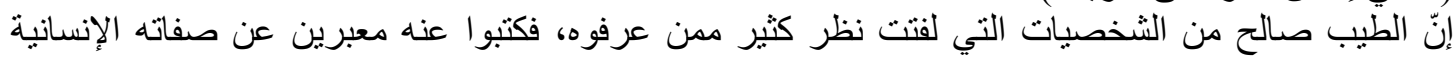

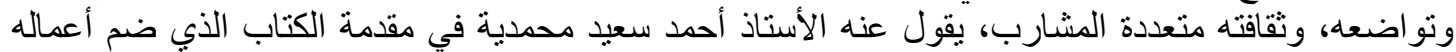

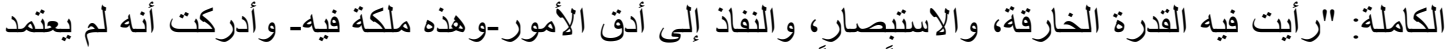

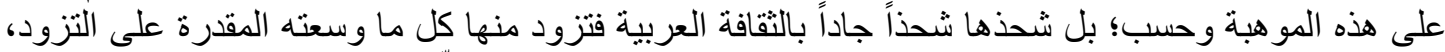

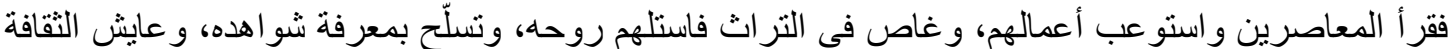

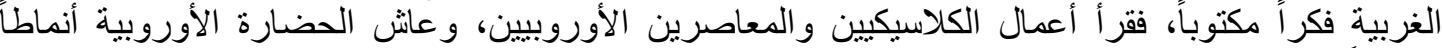
وسلوكاً وطريقة حياة ومنهج تفكير". 


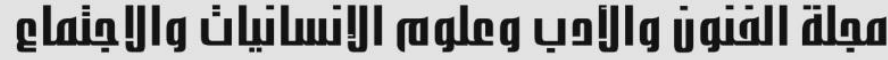

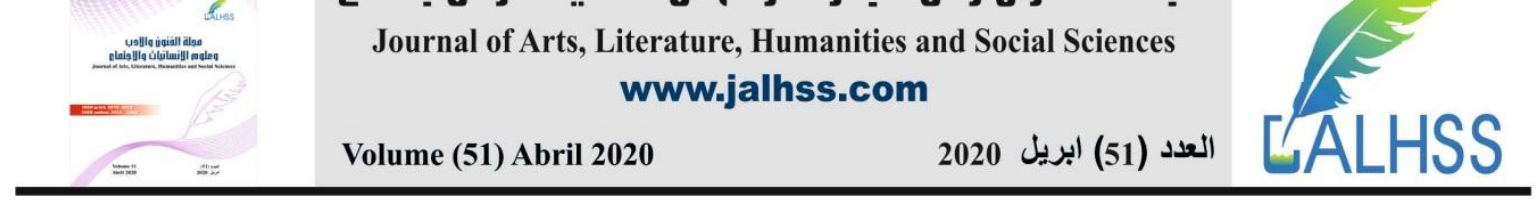

\section{رواية عرس الثباني}

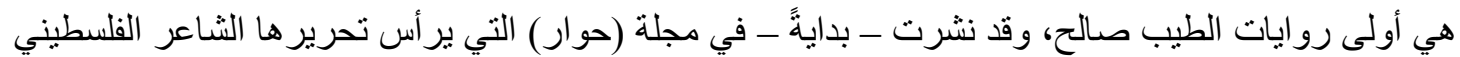

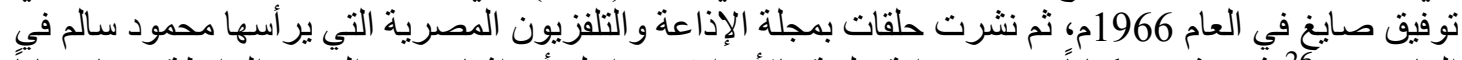

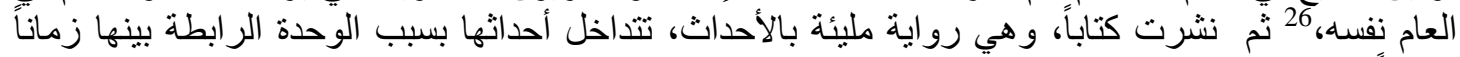

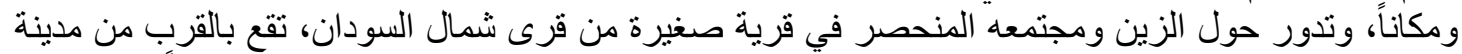

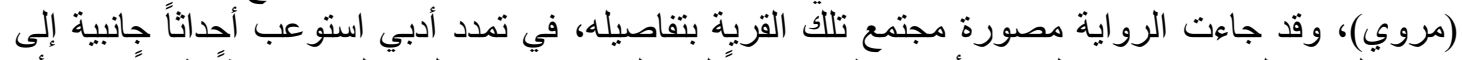

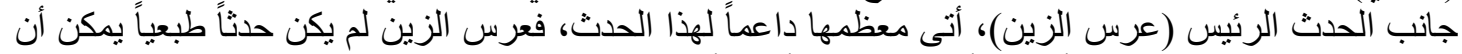

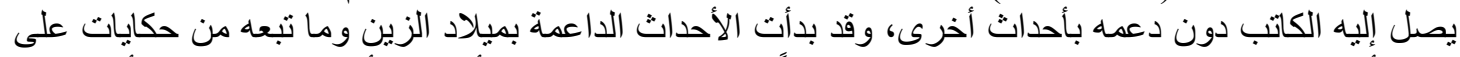

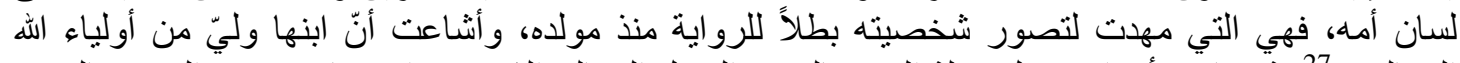

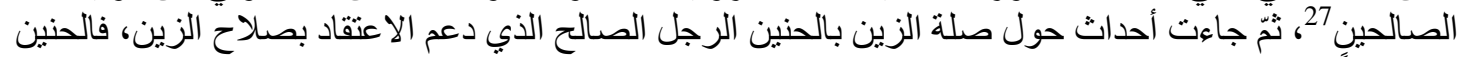

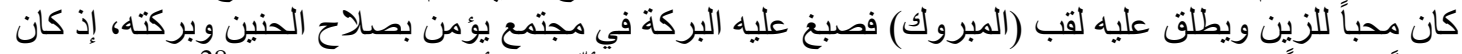

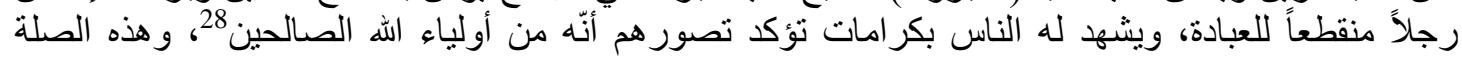

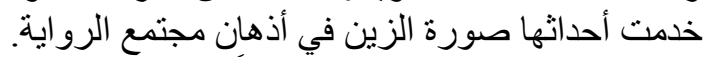

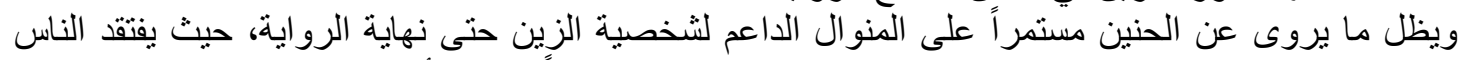
الزين يوم عرسه فيجدونه قد ذهب لقبر شيخه الحنين وجلس عنده الفي باكياً بردد: "أبونا الحنين إن كان ما مات كان كان

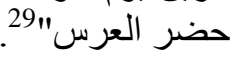
وثمة أحداث متعلقة بسيف الدين، تبدأ بنشأته وفسقه، وتمر بغضب و الده عليه حتى موته، ثم تَحولِ شخصيته في

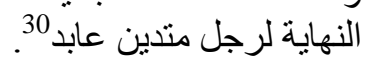

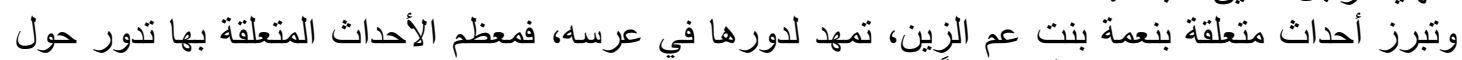

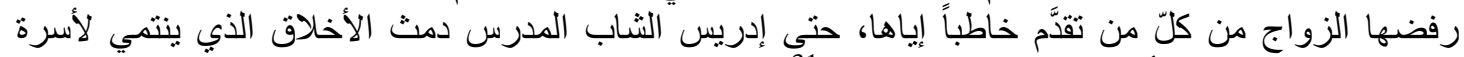

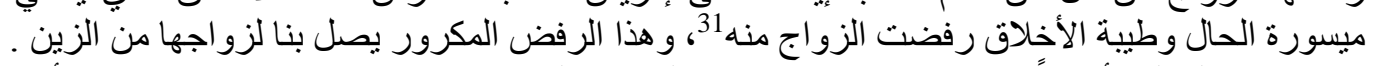

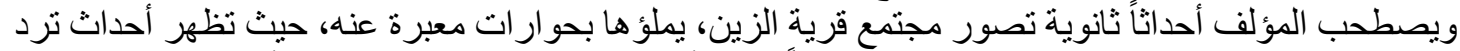

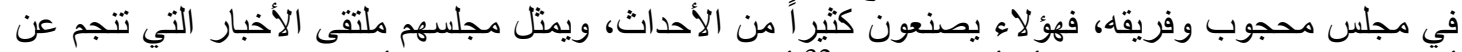

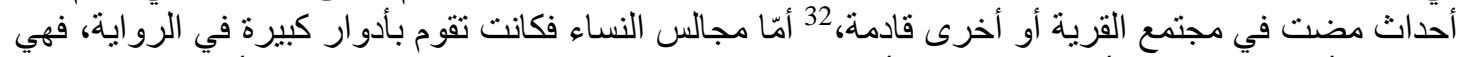

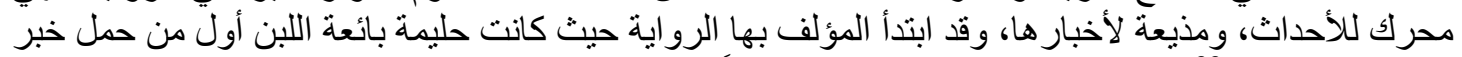

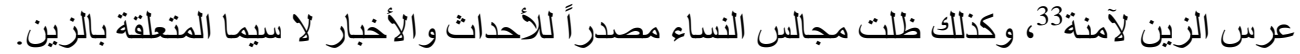

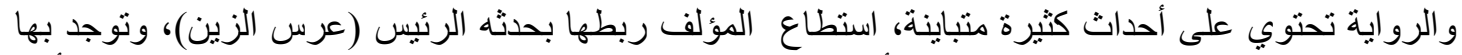

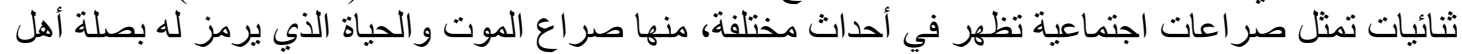

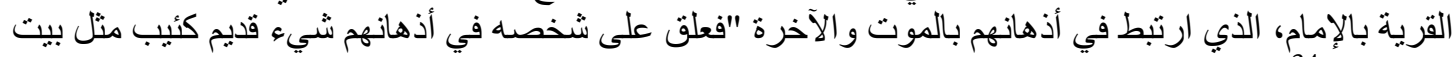

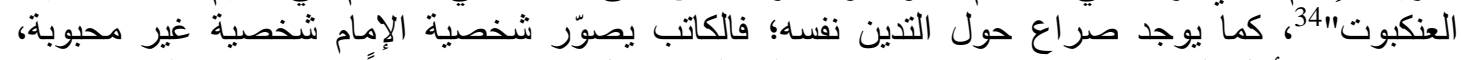

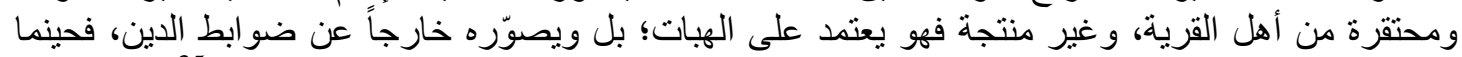

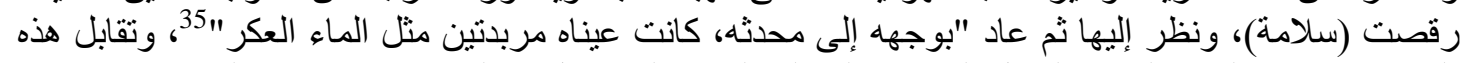

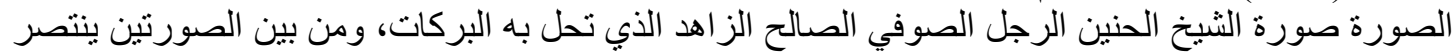
الكاتب للتندين على النسق الصورة الصني.

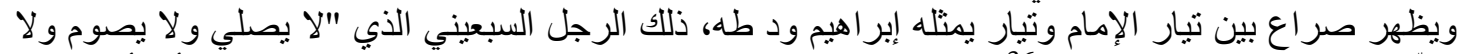

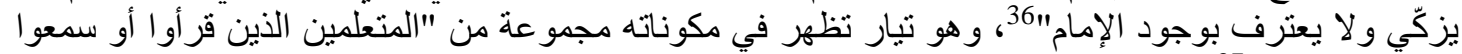

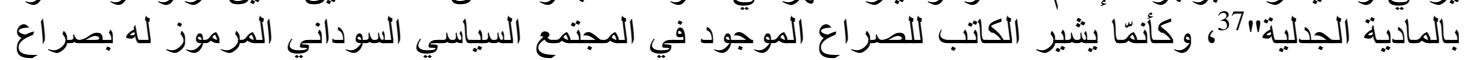
اليمين و اليسار. لقد بُنيت الرواية على زمن يتحرك بين الحاضر و الماضي، ومكان غير محدد، فهي في قرية من القرى المجاورة

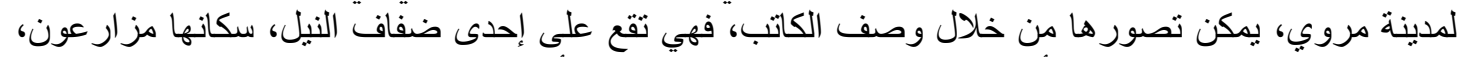
يهتمون بالزر اعة ويرتبطون بالأرض، ومجتمعها مغلق، تسري فيه الأخبار بسر عة. 


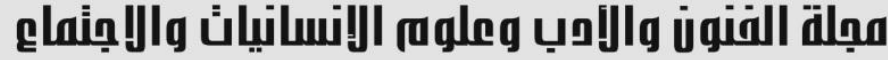

Journal of Arts, Literature, Humanities and Social Sciences

www.jalhss.com

و أهل قرية الزين مؤمنون بدينهم، منطلقاتهم صوفية، فهم يؤمنون بالكر امات، وخوارق العادات، تربطهح صلات

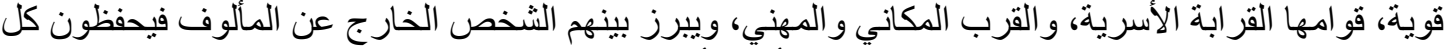

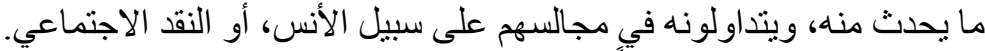

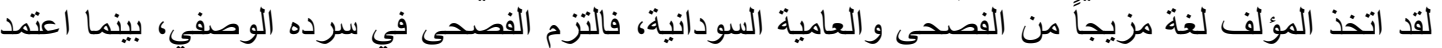

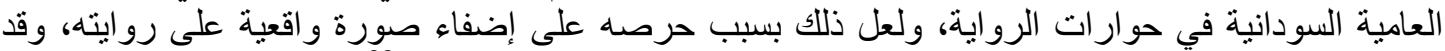

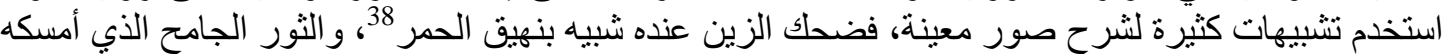

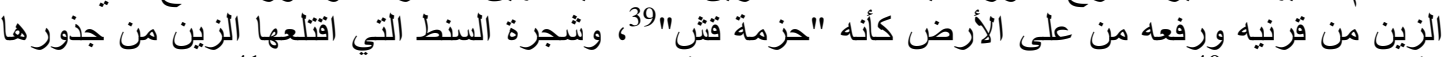

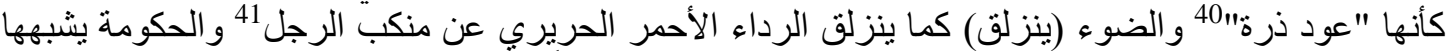

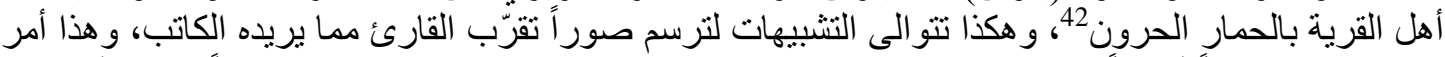
ربما يكون محموداً أسلوباً، ولكن الإكثار منه قد يحد خيال المنلقي، فما يرسمه المؤلف ــوصفاً. يمكن أن يغني عن كثرة التشبيهات.

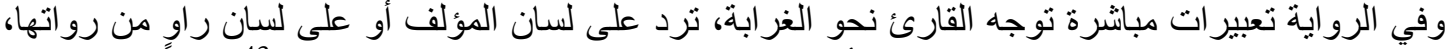

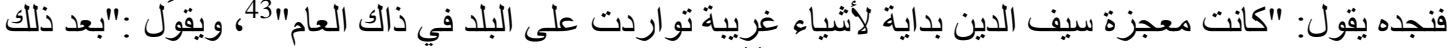

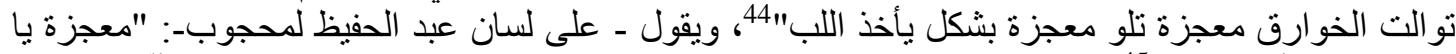
زول ما في أدنى شك"

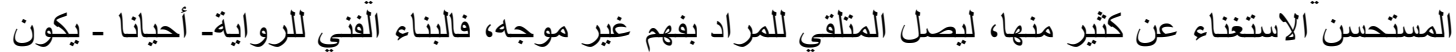

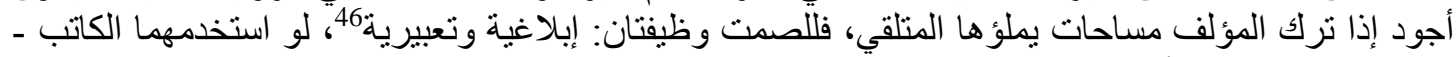

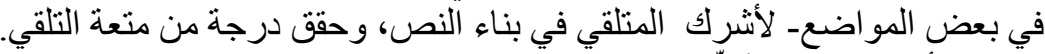

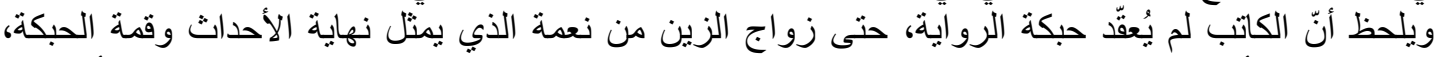

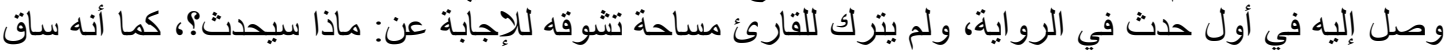

الأحداث حول نعمة ـ منذ البداية ـ إلى اتجاه زواجها من الزين، فأجاب عن كثير مما يشوق المتلقي للنّهاية.

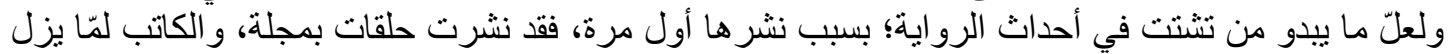

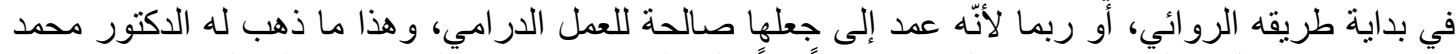

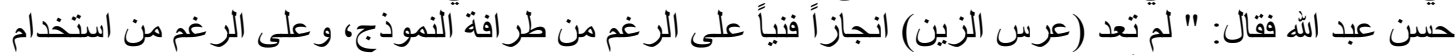

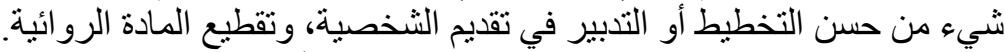

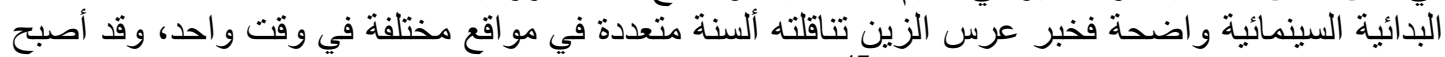

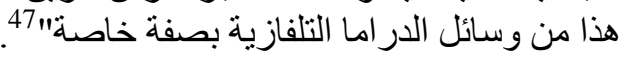

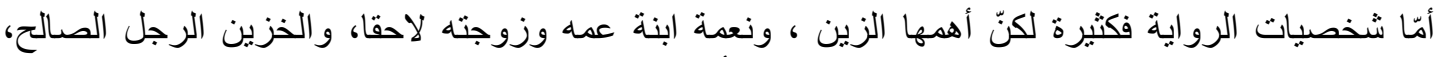

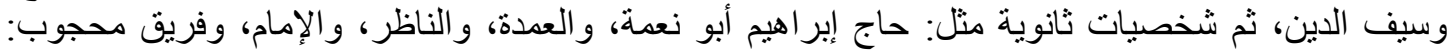

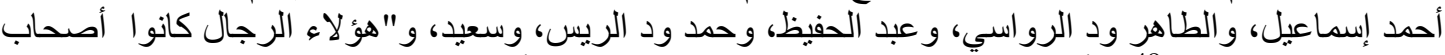

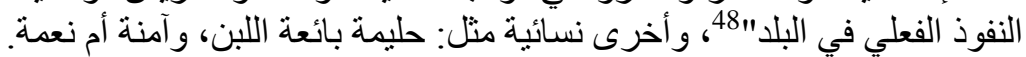

\section{المبحث الثالث \\ الغزابة في شخصيات الرواية}

الشخصية عنصر أساس في بناء الرواية يمثّل رمزاً يعرض من خلاله الراوي ما يريد، فهي "التي تقوم

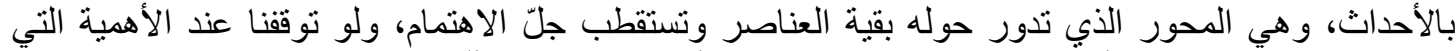

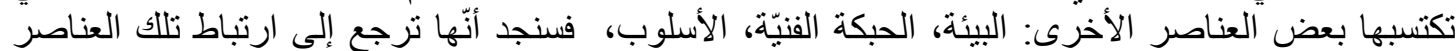

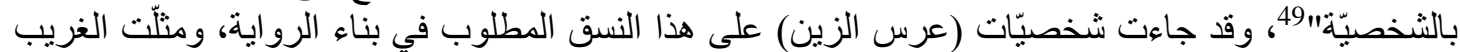

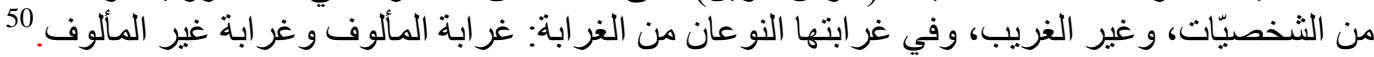

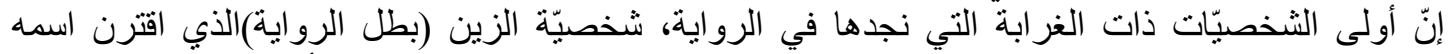
باسمها، وتظهر من خلال وصفه الجسدي وصفاته وسلوكه، يقول الراوي: "يولد الأطفال فيستقبلون الحياة 


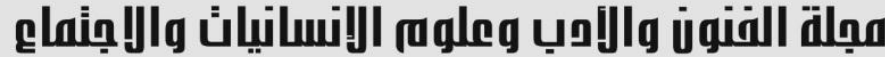

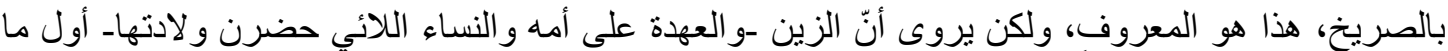

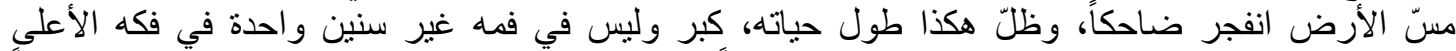

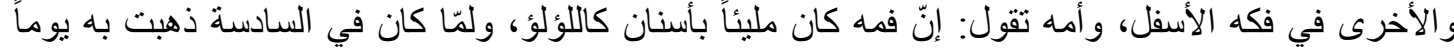

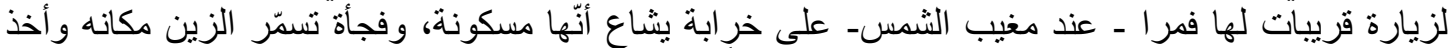

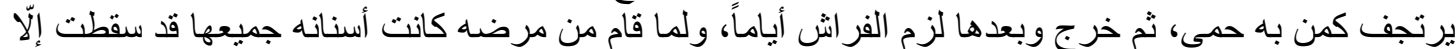
واحدة في فكه الأعلى وأخرى في في فكه الأسفل".

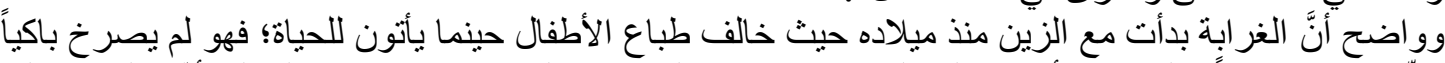

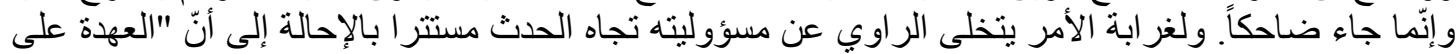

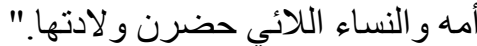

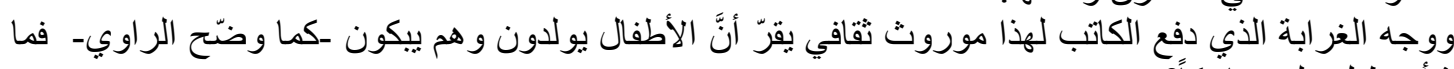

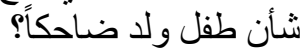
ثم ما تنفك الغر ابة تسير معه فيحدث حدث غريب يحوّل صورته ويهيئ المجتمع لثخصيّة أخرى؛ فأمه تثبير

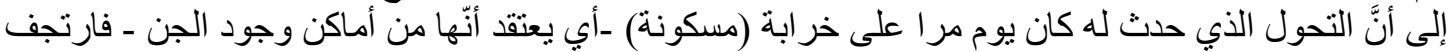

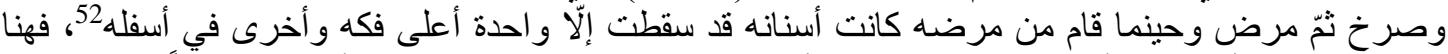

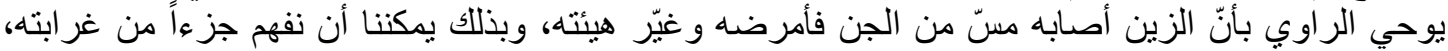

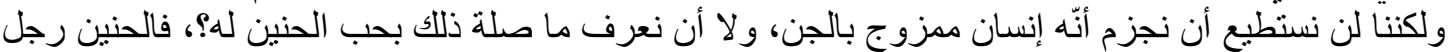

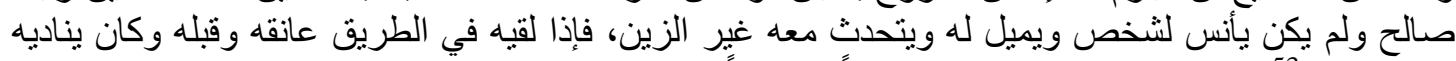

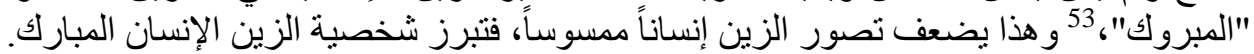

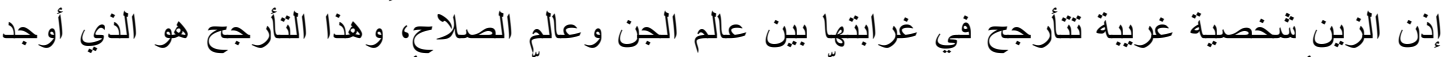

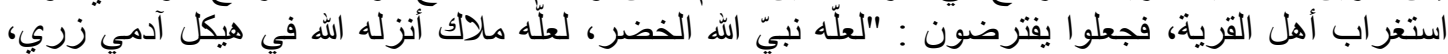

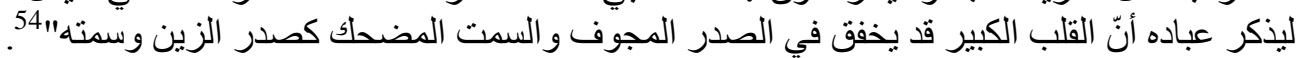

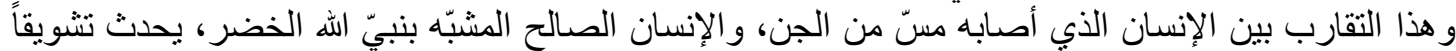

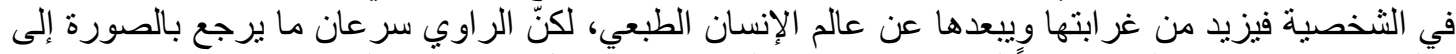

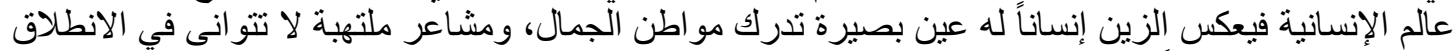

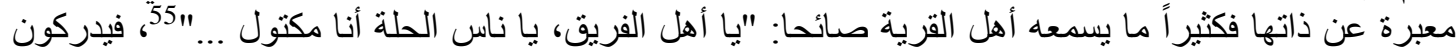

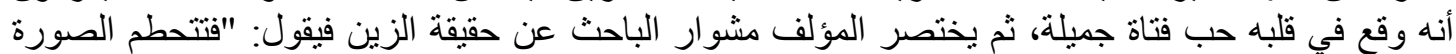

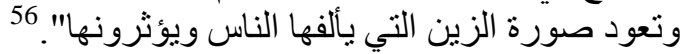

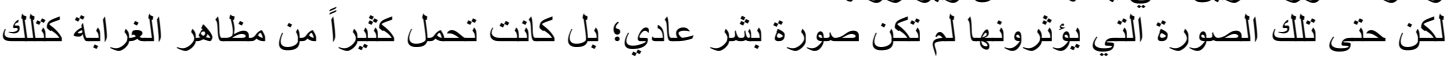

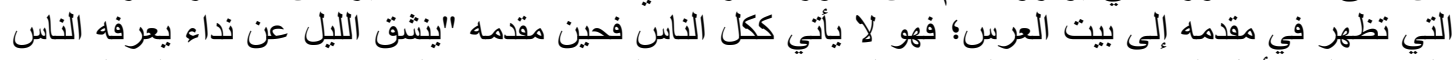

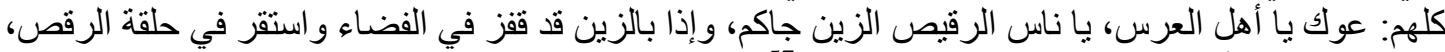

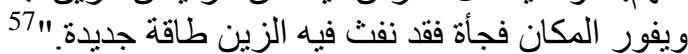

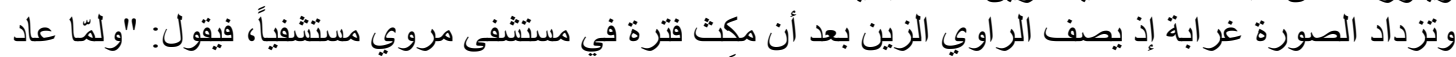

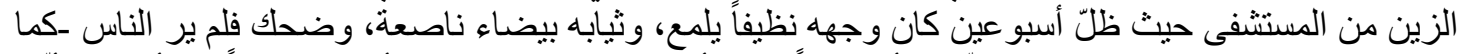

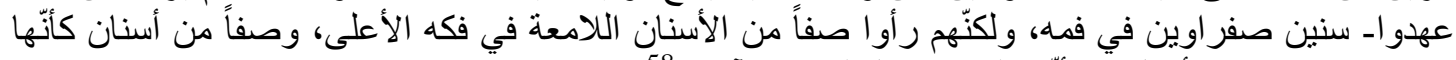

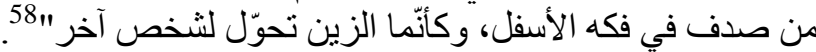

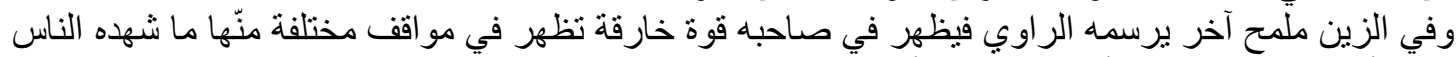

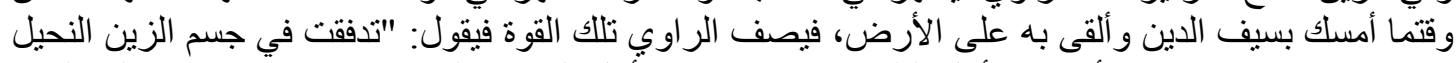

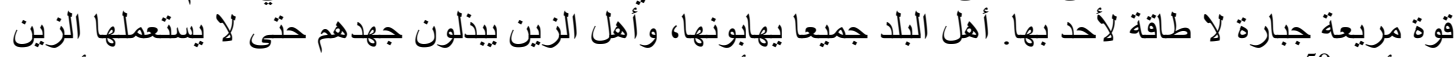

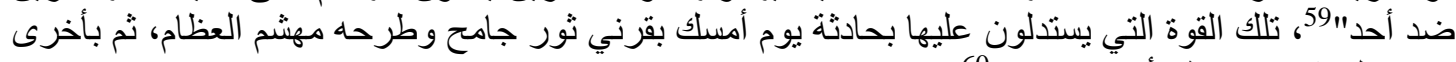

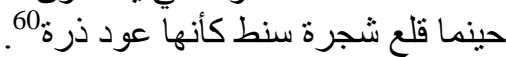

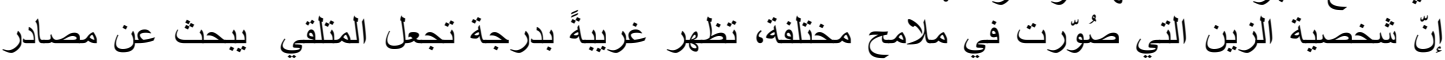

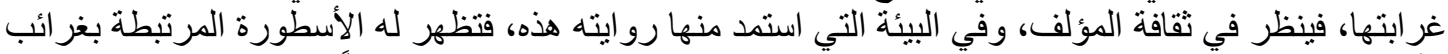
الأشياء مثل المساكن المهجورة التي يسكنها الجنّ، وما يمتد من ذالك الاعتقاد ممزوجاً بالمعتقدات المحيطة بعالم المبطة 


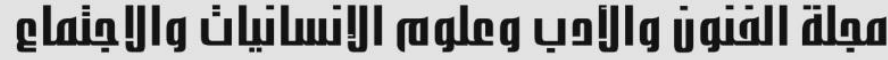 \\ bes Journal of Arts, Literature, Humanities and Social Sciences www.jalhss.com}

الجنّ و إصابته البشر ببعض التغير ات، وهذه الأساطير شيء مشوّق ومثير ، وتمثّل تبار اً فنباً غذّى شخصية الزين بكلّ تلك الأبعاد، وصور ها بطلاً غريباً، يجذب المتلقي للبحث عن مكنونه، فيسير معه بروح تتوقع كلّ غريب

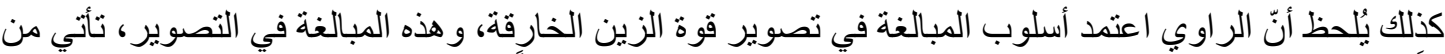

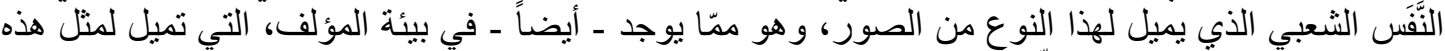

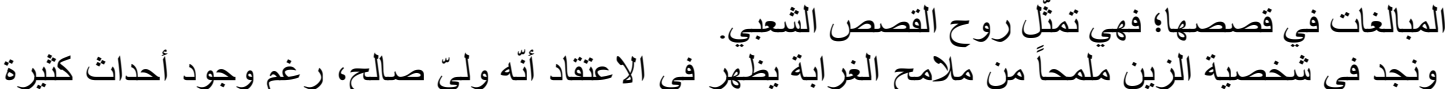

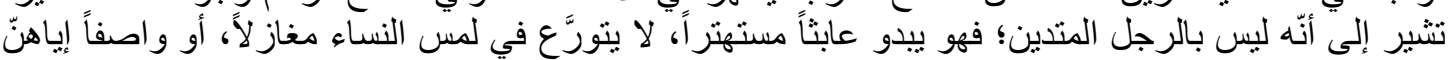

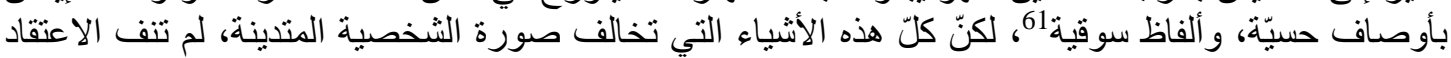

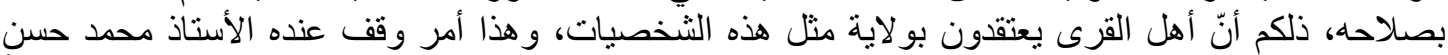

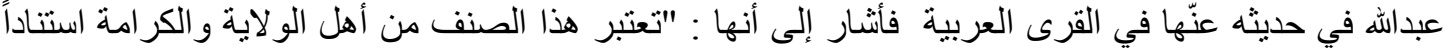

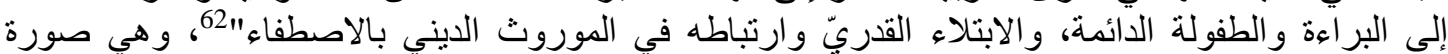

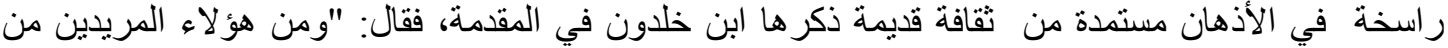

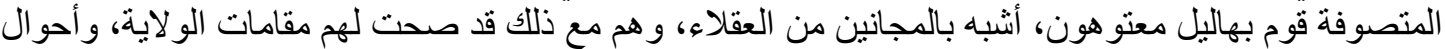

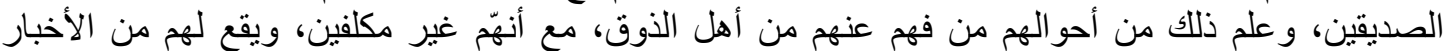

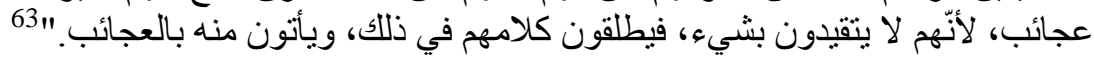

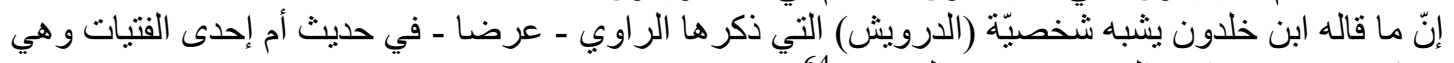

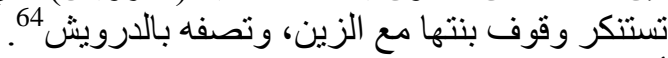

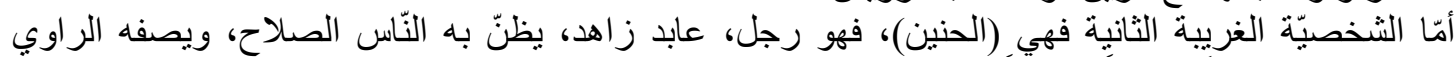

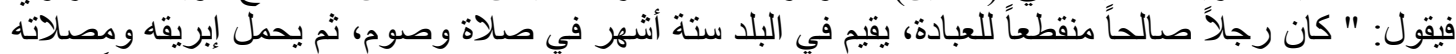

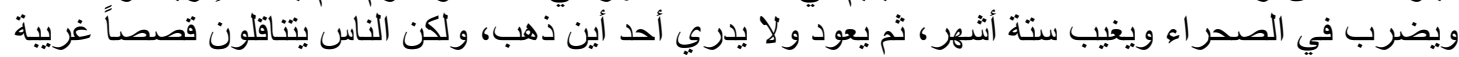

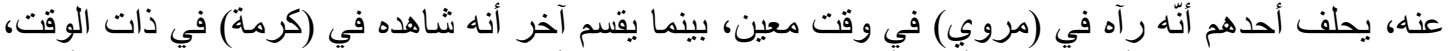

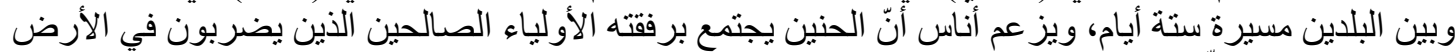

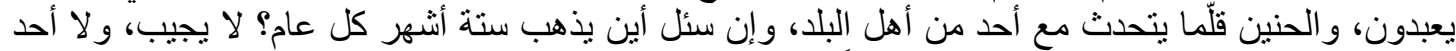

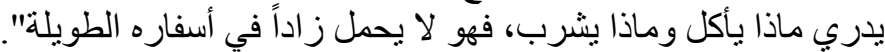

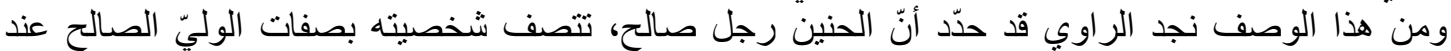

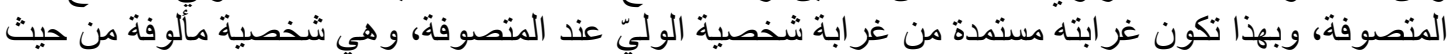

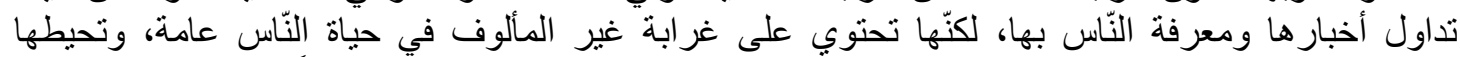

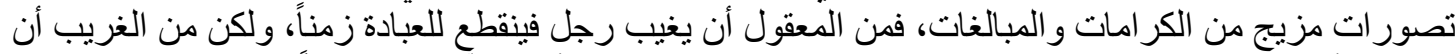

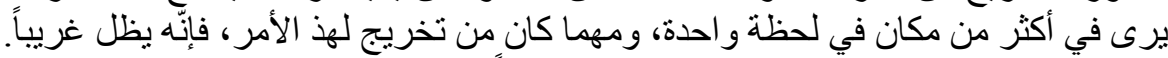

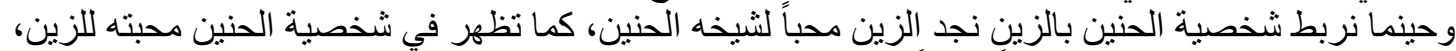

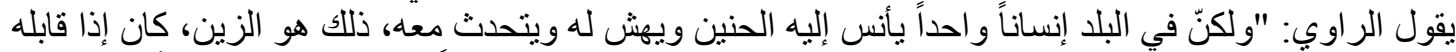

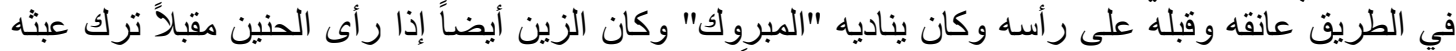

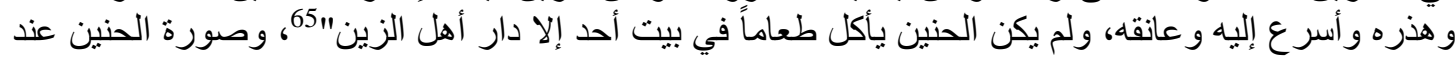

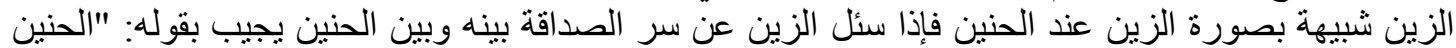
راجل مبروك"، و وهو ذات ما يقوله النه الحنين عنه.

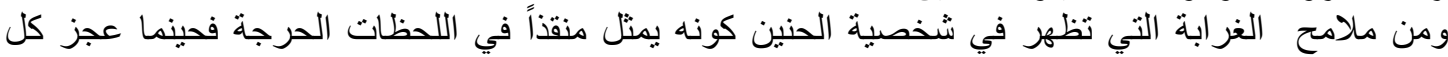

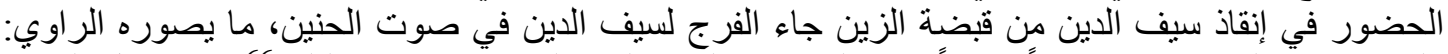

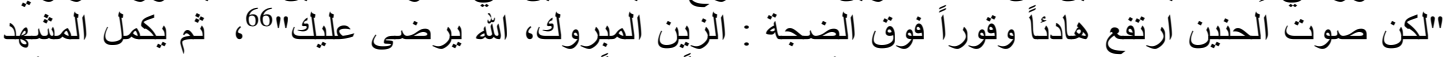

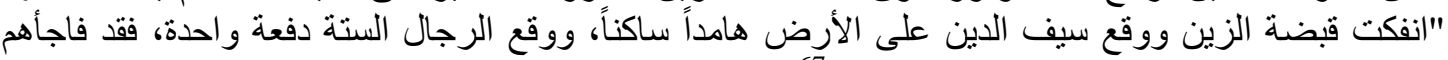
صوت الحنين وباغنهم الزين بسكونه الزين سفئئ.." 


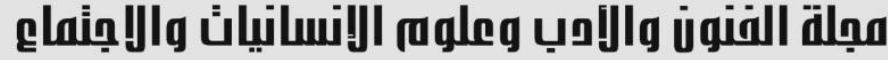

Journal of Arts, Literature, Humanities and Social Sciences www.jalhss.com

وتقوى ملامح الرجل الصالح في شخصية الحنين التي تتخلل السرد حينما يصرّح بها الر اوي وهو يصف الخئ الخير

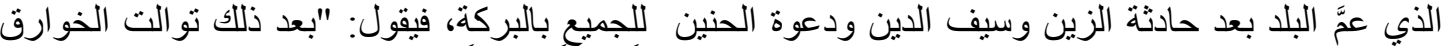

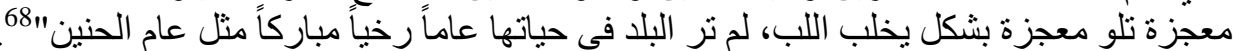

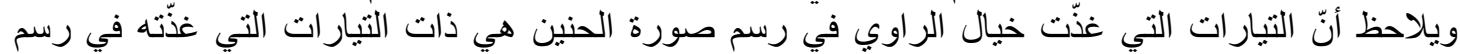

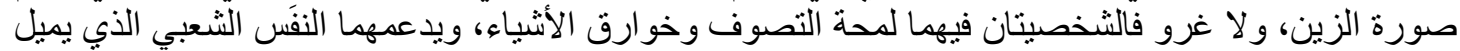

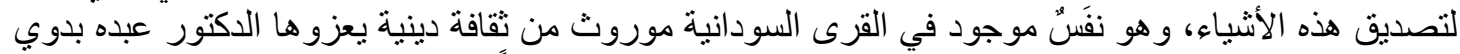

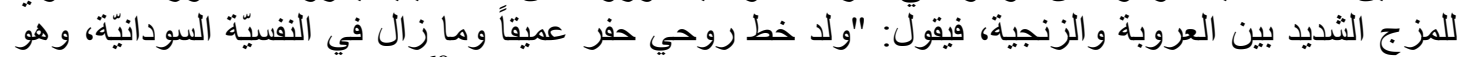

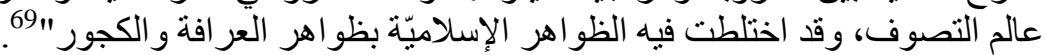

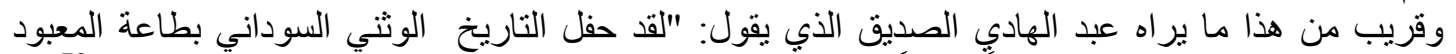

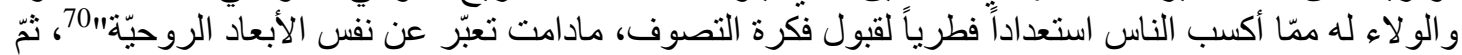

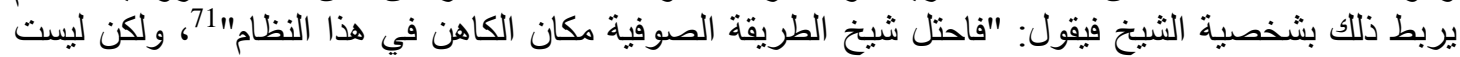

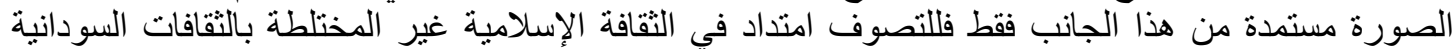

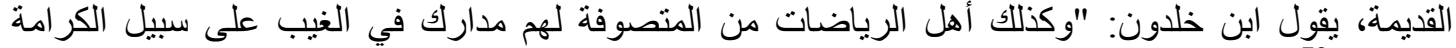

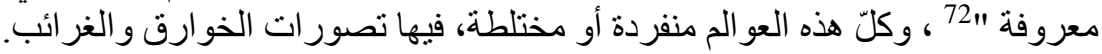

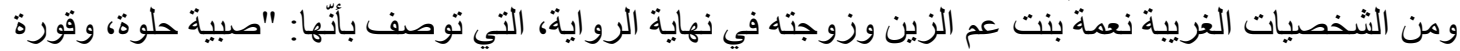

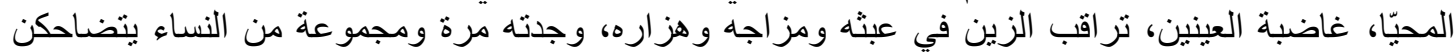

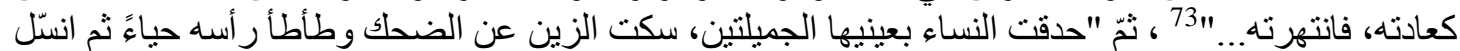

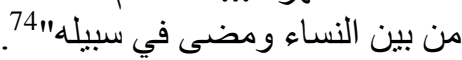

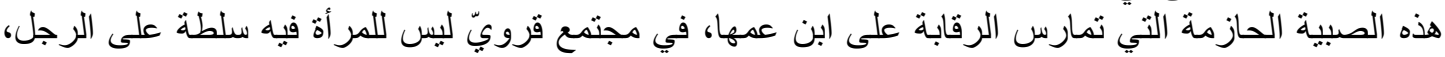

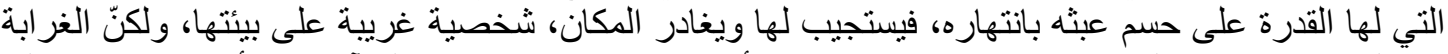

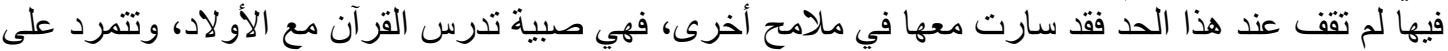

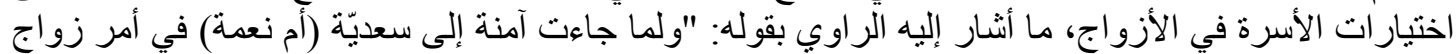

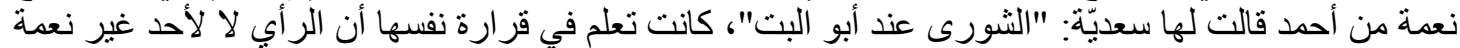

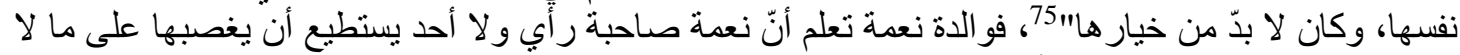

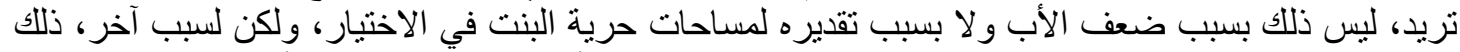

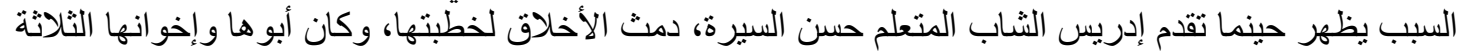

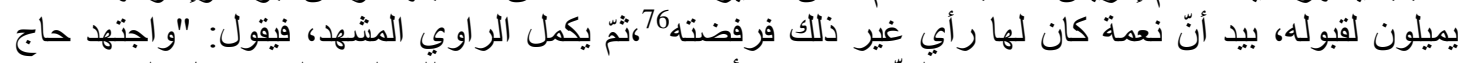

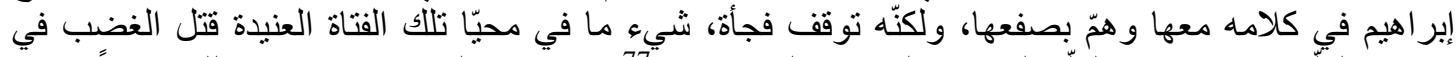

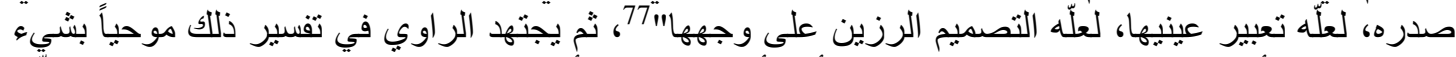

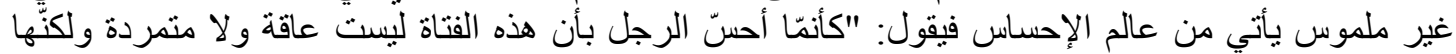

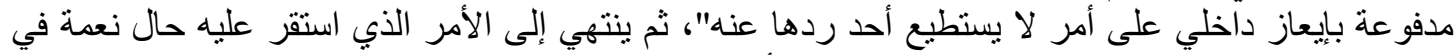

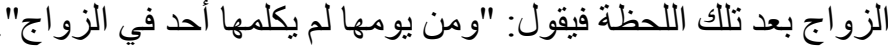

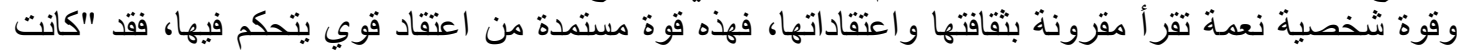

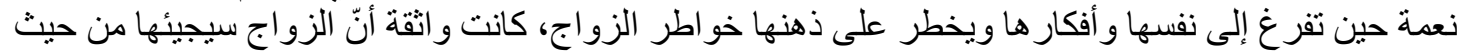

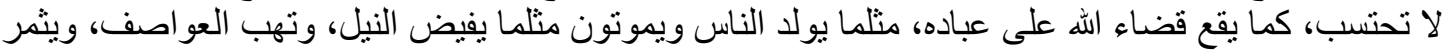

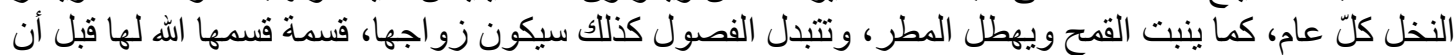

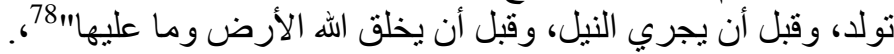

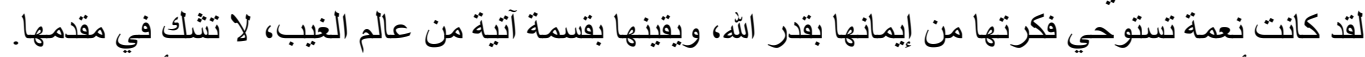

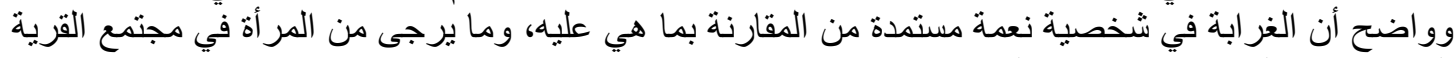

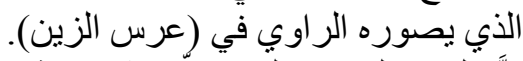

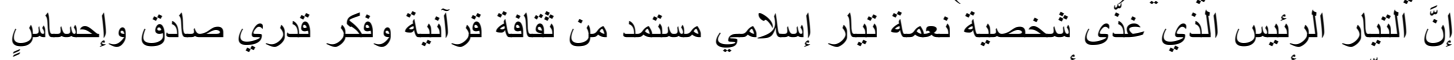
صوفيٍٍ عند أبيها، وتقديرِ من أخوتها. 


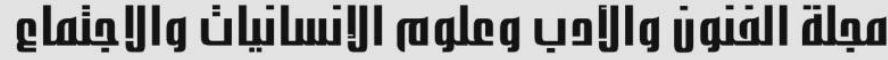

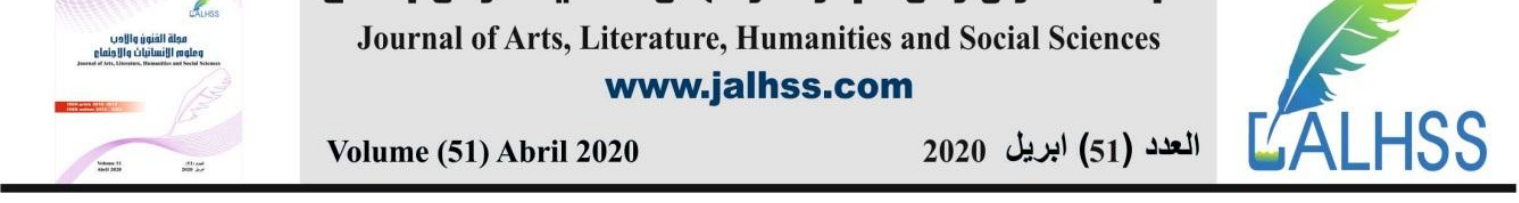

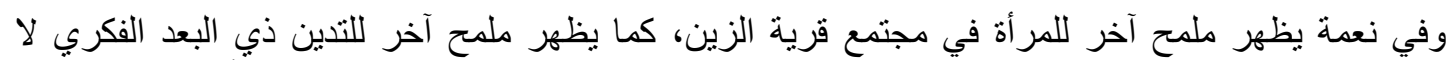

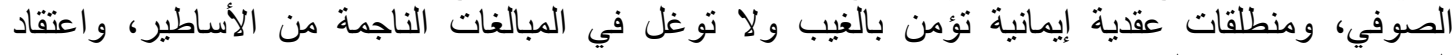
الكر امات، وخو وخوارق العادات.

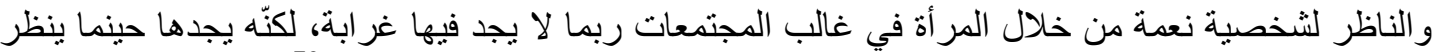

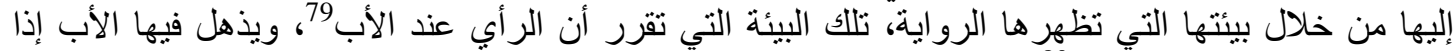

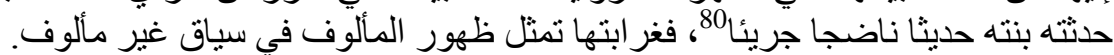

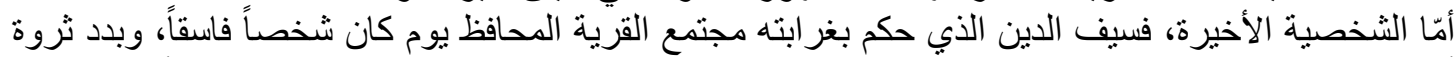

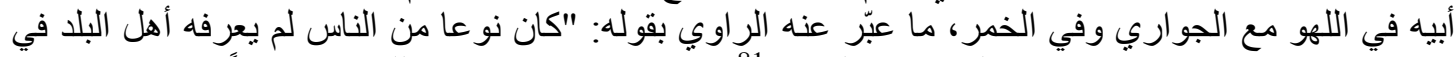

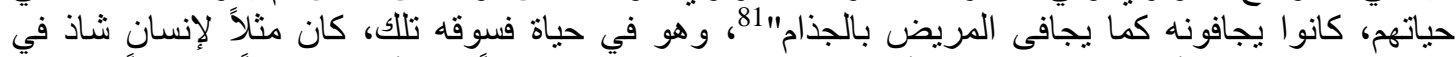

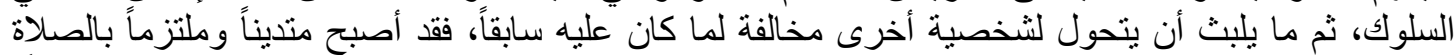

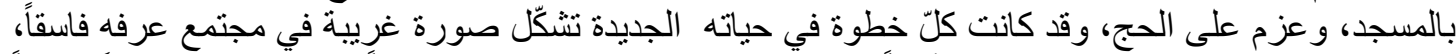

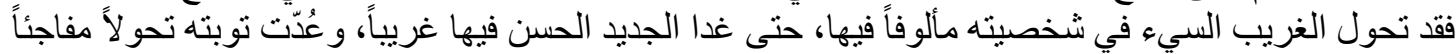

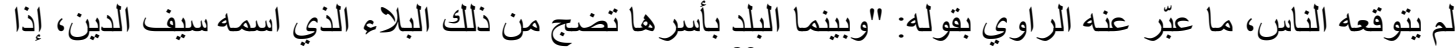

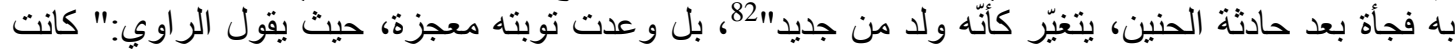

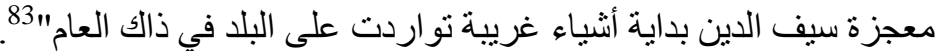

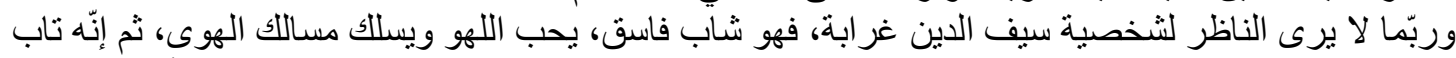

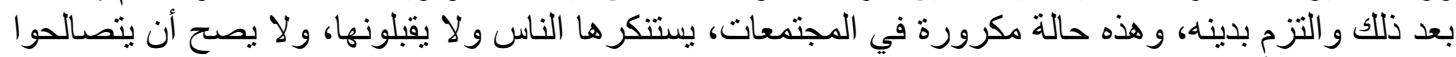

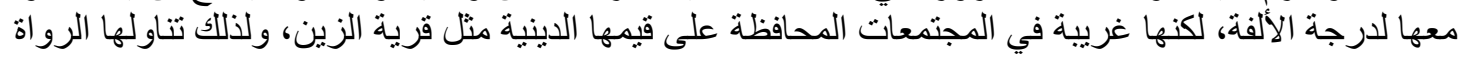
بروح الاستنكار و الدهشة و الإحساس بالغر ابة.

الخاتمة

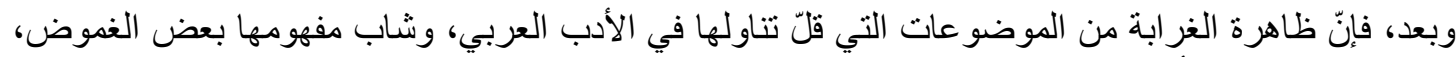

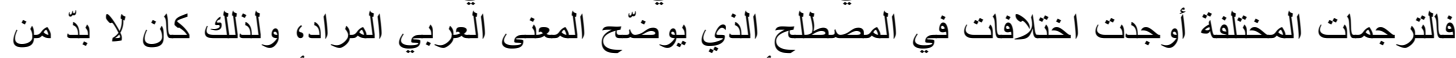

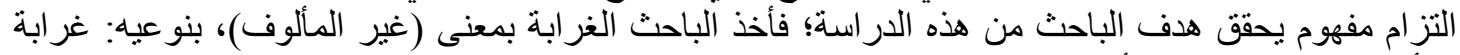

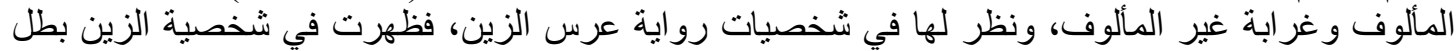
الرواية، ثم الثيخ الحنبن، ونعمة، والئ، وسيف الدين. وقد لاحظ الباحث أنّ المؤلف عالج تلأك الثخصيات مستنداً على إرث ثقافي بيئي، أساسه المعتقدات الدينية،

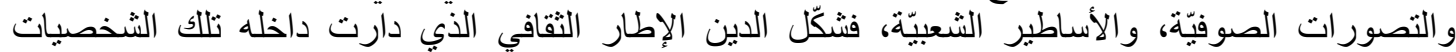

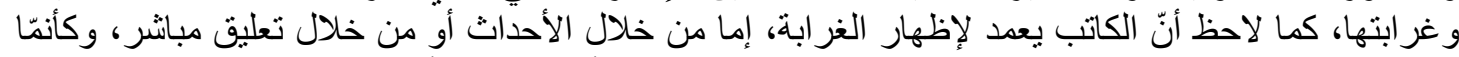

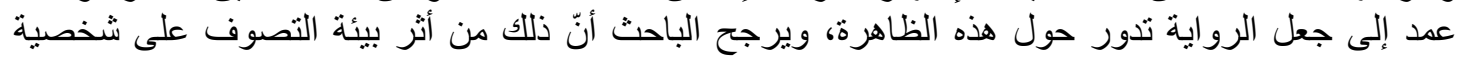
المؤلف.

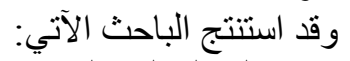

1. عالج المؤلف الثخصيات من خلال الموروث البيأي المحيط بها، حيث تصور دور كل و احدة منها من خلال البيئة فظهر فيها الغريب و غير الغريب.

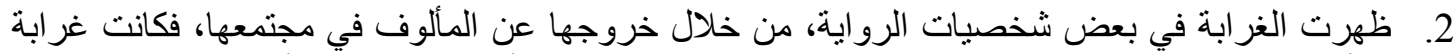

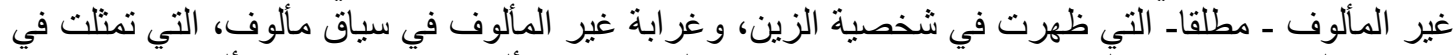

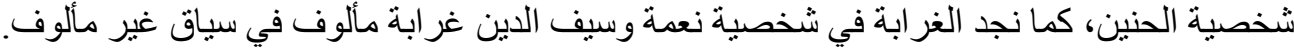

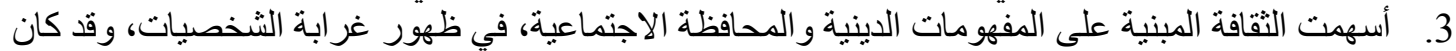

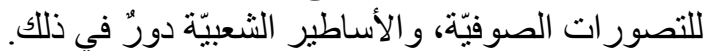

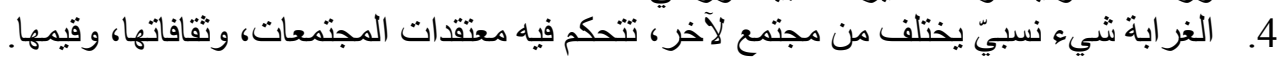

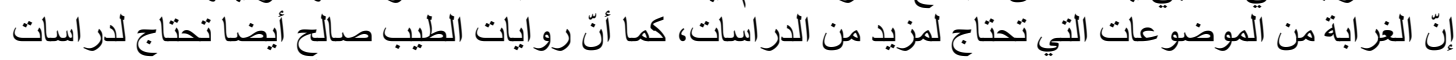

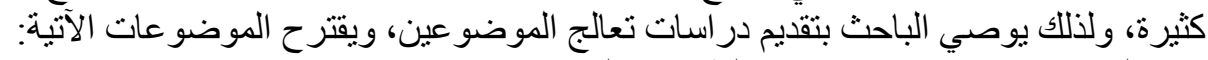

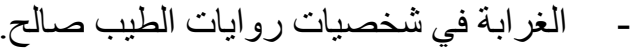




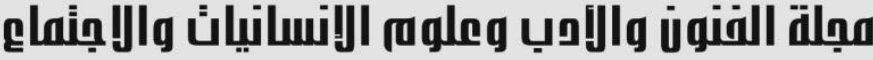

Journal of Arts, Literature, Humanities and Social Sciences
www.jalhss.com

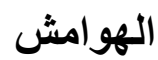

1 - شاكر عبد الحمبد، الغر ابة: المفهوم وتجلياته في الأدب، عالم المعرفة، الكويت، 1433هـ - 2010م، ص7. 2 - المرجع السابق، الصفحة نفسها. 3

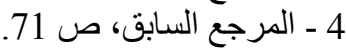

5 - عبد الفتاح كيليطو، الغرابة (دراسة بنيوية في الأدب العربي)، دار توبقال للنشر، الدار البيضاء، ط3، 2006م، ص69.

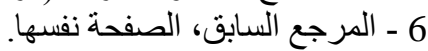

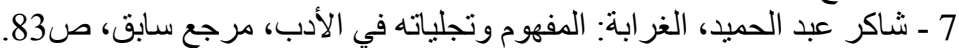

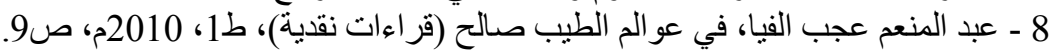

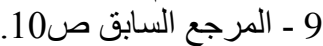

10 - عون الثريف قاسم، الإسلام و العروبة في السودانـ دراسات في الحضارة واللغة، دار الجيل، بيروت ــار

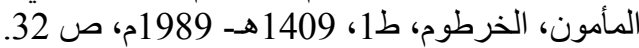

11 - الطيب صالح، الأعمال الكاملة، دار العودة، بيروت، 1989 1996، الصفحات: 7،8.

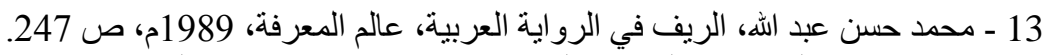

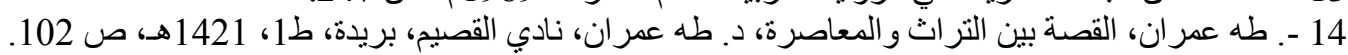

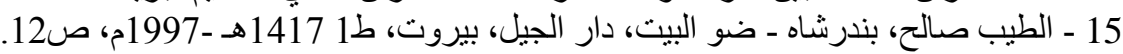

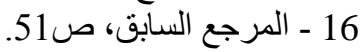

17 - حلمي محمد القاعود، النقد الأدبي الحديث (بداياته وتطوره)، دار النشر الدولي للنشر والتوزيع، 1427هـ - 2006م،

ص34.

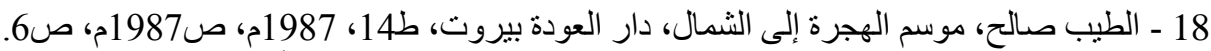

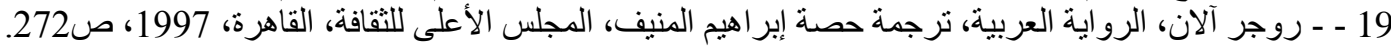

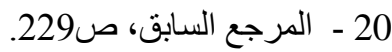

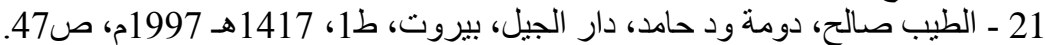

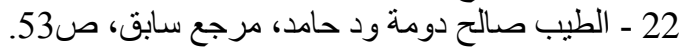

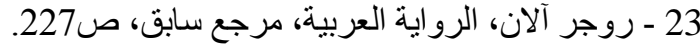

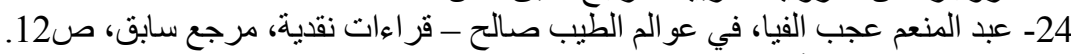

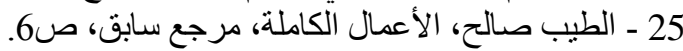

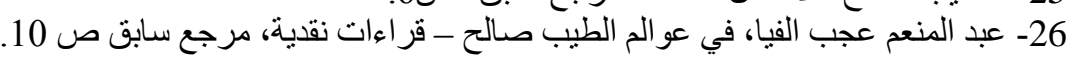

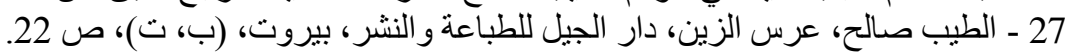
28 - المرجع السابق، الصفحة نفسها.

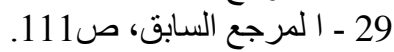

30 - المرجع السابق، ص59.

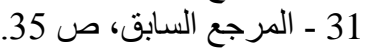

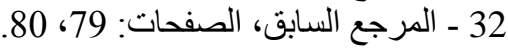

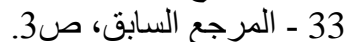

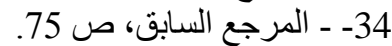

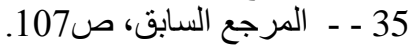

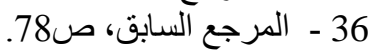

37 - المرجع السابق، الصفحة نفسها.

38- المرجع السابق، ص9.

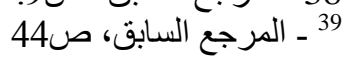




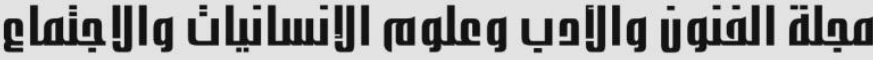

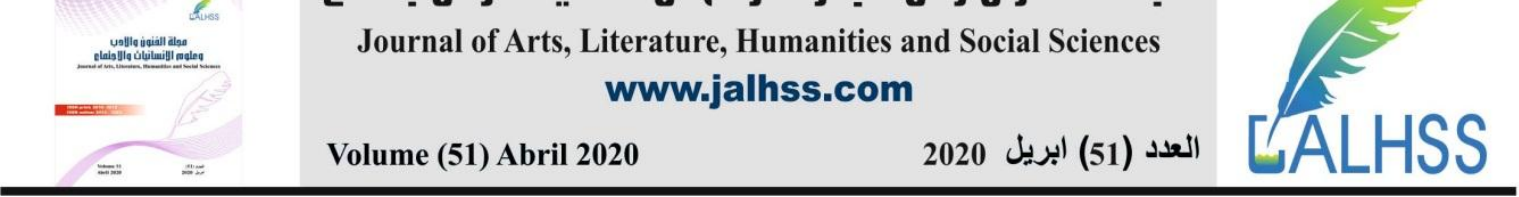

$$
\begin{aligned}
& \text { 40- المرجع السابق، الصفحة السابقة نفسها. }
\end{aligned}
$$

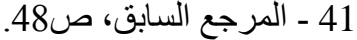

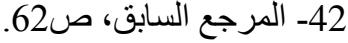

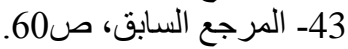

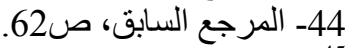

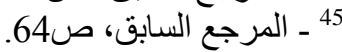

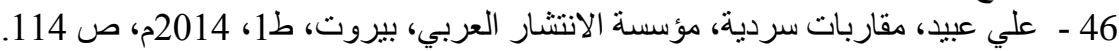

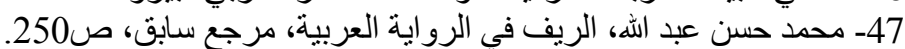

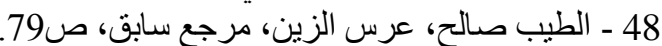

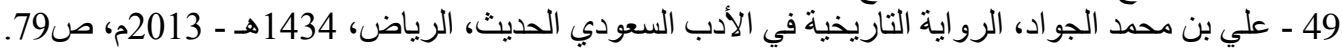

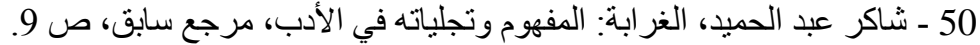

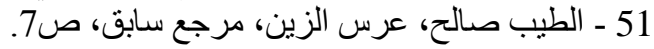

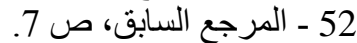

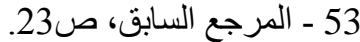

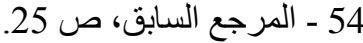

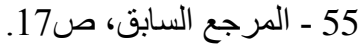

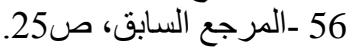

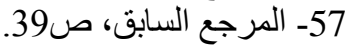

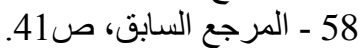

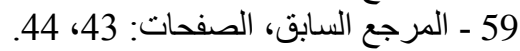

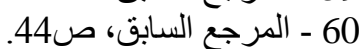

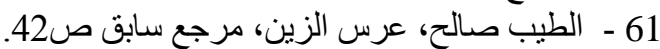

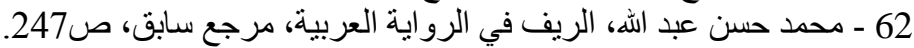

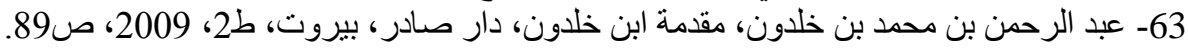

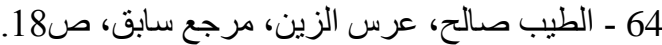

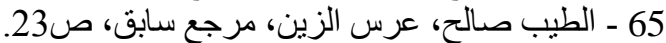

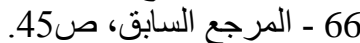

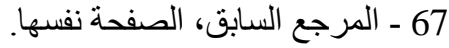

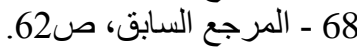

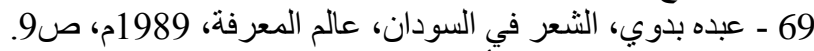

70 - عبد الهادي الصديق، أصول الثُعر السوداني، دار جامعة الخرطوم للنشر، الخرطوم، ط2، 1989م، ص80

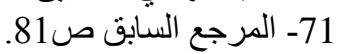

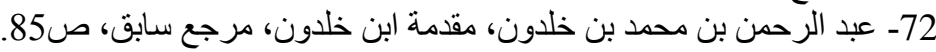

73- الطيب صالح، عرس الزين، مرجع سابق، 25 - 25.

(المرجع السابق، الصفحة نفسها.

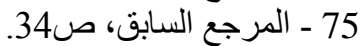

76 - المرجع السابق، ص35.

77 ـ المرجع السابق، الصفحة نفسيا.

78 78 - المرجع السابق، الصفحات:

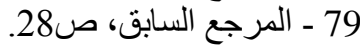

80 - المرجع السابق، 33 - 33.

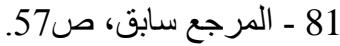

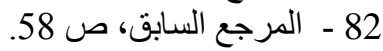

83 - المرجع السابق، ص60. 


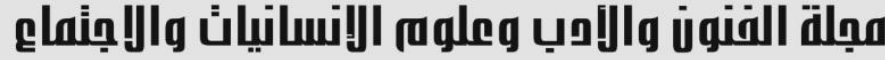

Journal of Arts, Literature, Humanities and Social Sciences

www.jalhss.com

\section{1. الطيب صالح، موسم الهجرة إلى الثمال، دار العودة، بيروت، ط14، 1987م.

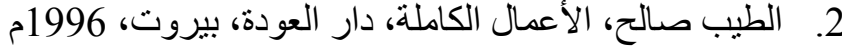

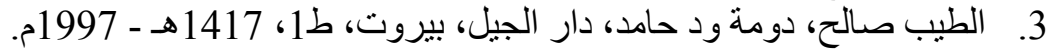

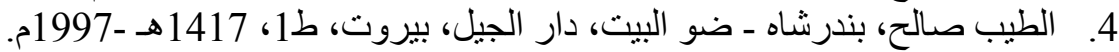

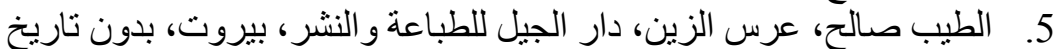

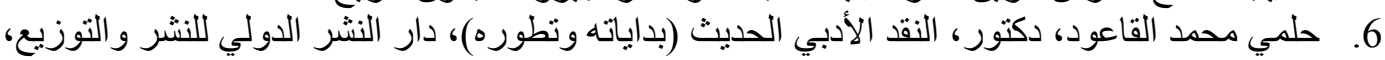

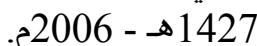

7. عبد الفتاح كيليطو، الأدب و الغرابة (در اسة بنوية في الأدب العربي)، دار توبقال للنشر، الدار البيضـاء، ط3، 2006.

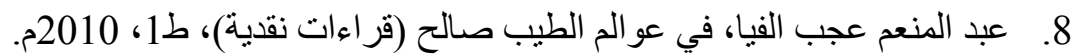

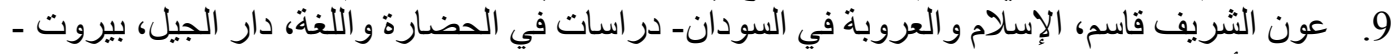

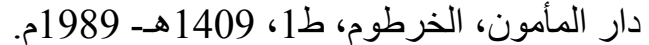

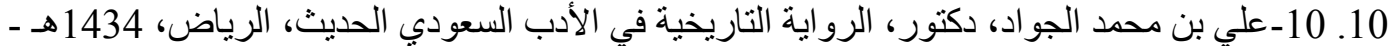
2013 2013

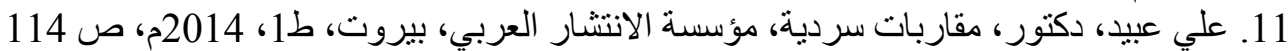

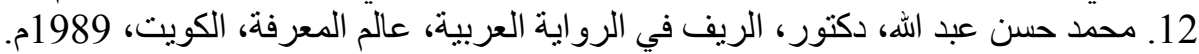

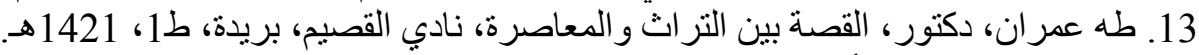

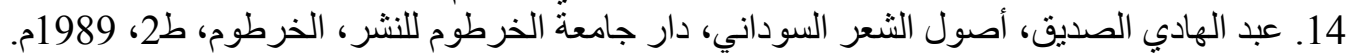

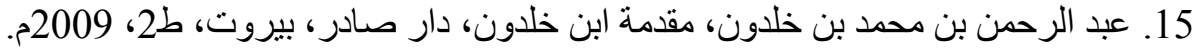

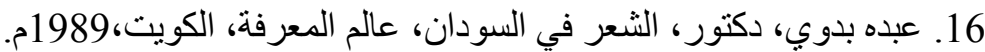

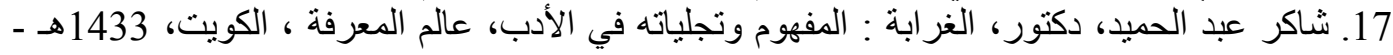
2010 


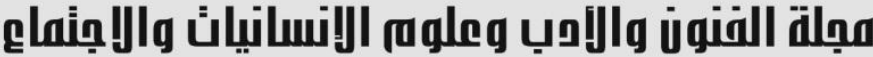

Journal of Arts, Literature, Humanities and Social Sciences

www.jalhss.com

\section{References}

1. Al-Tayeb Salih, Season of Migration to the North, Dar Al-Awda, Beirut, 14th edition, 1987 AD.

2. Al-Tayeb Saleh, Complete Works, Dar Al-Awda, Beirut, 1996

3. Al-Tayyeb Salih, Duma and Hamed, Dar Al-Jeel, Beirut, 1st ed, 1417AH1997AD.

4. Al-Tayeb Salih, Bandarshah - Daw Al-Bayt, Dar Al-Jeel, Beirut, 1st ed, 1417AH-1997 CE.

5. Al-Tayeb Salih, Al-Zain Wedding, Dar Al-Jeel for Printing and Publishing, Beirut, without date

6. Helmy Muhammad Al-Qaoud, Doctor, Modern Literary Criticism (Its beginnings and development), International Publishing House for Publishing and Distribution, $1427 \mathrm{AH}-2006 \mathrm{AD}$.

7. Abdel-Fattah Kelaito, Literature and Strangeness (a structural study of Arabic literature), Toubkal Publishing House, Casablanca, 3rd floor, 2006.

8. Abdel Moneim Ajab Alfia, in the worlds of Tayyib Salih (critical readings), 1st edition, 2010 AD.

9. Aoun Al-Sharif Qassem, Islam and Arabism in Sudan - Studies in Civilization and Language, Dar Al-Jeel, Beirut - Dar Al-Mamoun, Khartoum, 1st edition, 1409 AH - 1989 AD.

10. 10 - Ali bin Muhammad Al-Jawad, Dr., the historical novel in modern Saudi literature, Riyadh, 1434 AH - 2013 AD.

11. Ali Obaid, Doctor, Narrative Approaches, Arab Publishing Organization, Beirut, 1st edition, 2014AD, p. 114

12. Muhammad Hassan Abdullah, Doctor, Al-Reef in the Arabic Novel, The World of Knowledge, Kuwait, 1989.

13. Taha Imran, Doctor, The Story between Heritage and Contemporaryity, AlQassim Club, Buraidah, I 1, 1421 AH.

14. Abdul Hadi Al-Siddiq, The Origins of Sudanese Poetry, University of Khartoum Publishing House, Khartoum, 2nd edition, 1989 AD.

15. Abdul Rahman bin Muhammad bin Khaldoun, Introduction to Ibn Khaldun, Dar Sader, Beirut, 2nd edition, 2009 AD.

16. Abdo Badawi, Doctor, Poetry in Sudan, The World of Knowledge, Kuwait, 1989.

17. Shaker Abdul Hamid, Doctor, Strangeness: The Concept and its Manifestations in Literature, The World of Knowledge, Kuwait, 1433 AH 2010 AD. 